Development

\title{
Erythropoietin Stimulates GABAergic Maturation in the Mouse Hippocampus
}

\author{
Kasifa Khalid, ${ }^{1,3, *}$ Julia Frei,, ${ }^{1, *}$ Mostafa A. Aboouf, ${ }^{2}$ Christina Koester-Hegmann,, ${ }^{1,2}$ Max Gassmann, ${ }^{2}$ \\ Jean-Marc Fritschy, ${ }^{1,3}$ and ${ }^{-}$Edith M. Schneider Gasser ${ }^{1,2,3}$
}

https://doi.org/10.1523/ENEURO.0006-21.2021

\begin{abstract}
${ }^{1}$ Institute of Pharmacology and Toxicology, Neuroprotection Group, University of Zurich, Zurich 8057, Switzerland, ${ }^{2}$ Institute of Veterinary Physiology, Vetsuisse Faculty, and Zurich Center for Integrative Human Physiology, University of Zurich, Zurich 8057, Switzerland, and ${ }^{3}$ Neuroscience Centre Zurich, University of Zurich and Eidgenössische Technische Hochschule Zurich, Zurich 8057, Switzerland
\end{abstract}

\section{Visual Abstract}

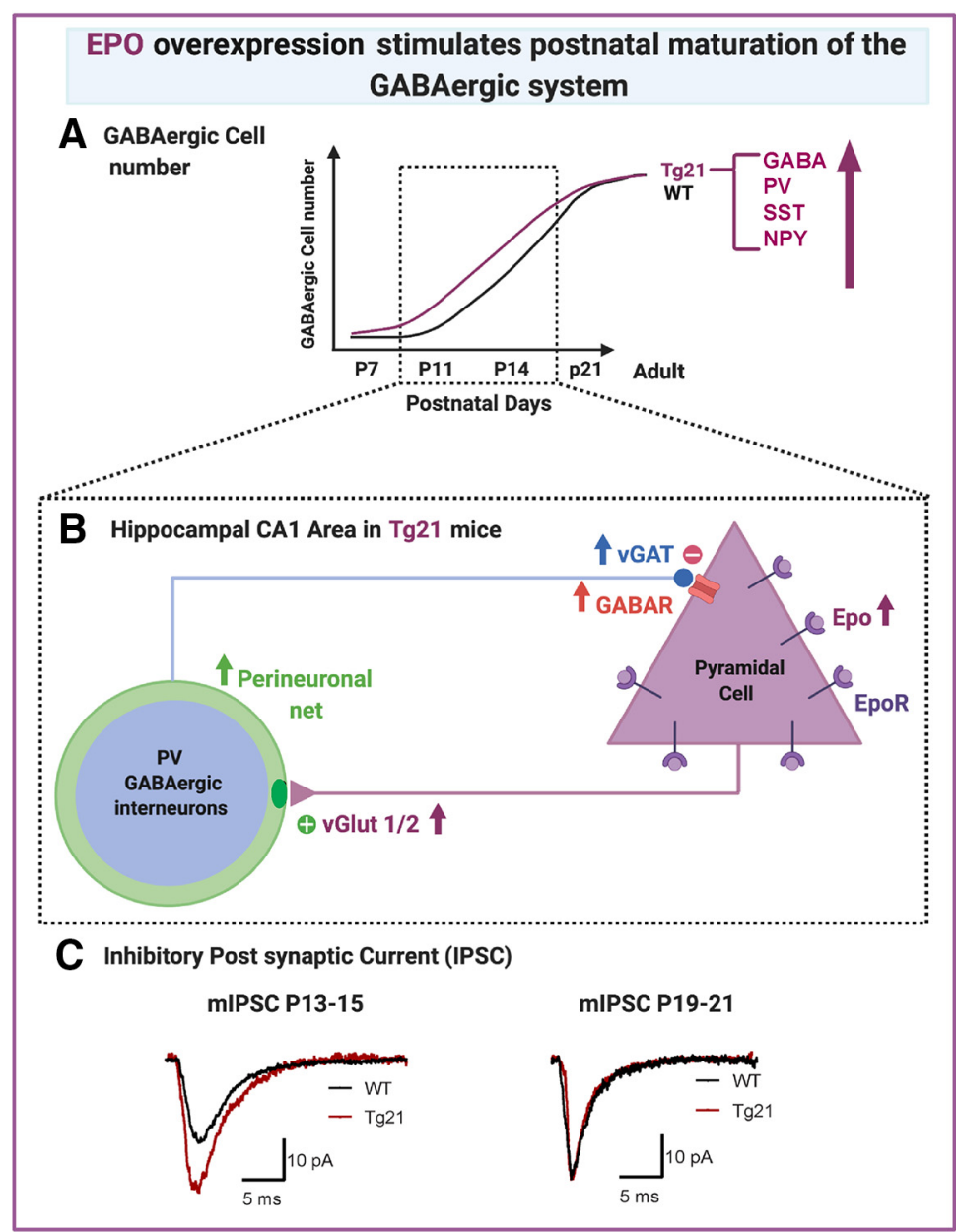

Several neurodevelopmental disabilities are strongly associated with alterations in GABAergic transmission, and therapies to stimulate its normal development are lacking. Erythropoietin (EPO) is clinically used in neonatology to mitigate acute brain injury, and to stimulate neuronal maturation. Yet it remains unclear whether EPO 


\section{Significance Statement}

Using a mouse model that overexpresses recombinant human erythropoietin (EPO) in the CNS, we observed stimulation of the postnatal maturation of GABAergic transmission in the hippocampus, notably accelerated maturation of parvalbumin (PV)+ interneurons, enhanced glutamatergic inputs onto these interneurons, and enhanced IPSCs onto pyramidal cells. We show that EPO receptors (EPORs) are expressed on pyramidal cells, therefore the impact of EPO on GABAergic maturation is likely to be indirect. Our data show that EPO can modulate hippocampal network maturation and support ongoing trials of the use of EPO in clinical neonatology to stimulate neuronal maturation after perinatal brain injury (PBI).

can stimulate maturation of the GABAergic system. Here, with the use of a transgenic mouse line that constitutively overexpresses neuronal EPO (Tg21), we show that EPO stimulates postnatal GABAergic maturation in the hippocampus. We show an increase in hippocampal GABA-immunoreactive neurons, and postnatal elevation of interneurons expressing parvalbumin (PV), somatostatin (SST), and neuropeptide Y (NPY). Analysis of perineuronal net (PNN) formation and innervation of glutamatergic terminals onto PV + cells, shows to be enhanced early in postnatal development. Additionally, an increase in GABA $A_{A}$ ergic synapse density and IPSCs in CA1 pyramidal cells from Tg21 mice is observed. Detection of EPO receptor (EPOR) mRNA was observed to be restricted to glutamatergic pyramidal cells and increased in Tg21 mice at postnatal day $(P) 7$, along with reduced apoptosis. Our findings show that EPO can stimulate postnatal GABAergic maturation in the hippocampus, by increasing neuronal survival, modulating critical plasticity periods, and increasing synaptic transmission. Our data supports EPO's clinical use to balance GABAergic dysfunction.

Key words: EPOR; inhibition; interneurons; parvalbumin; perineuronal nets; postnatal development

\section{Introduction}

Perinatal brain injury (PBI) might lead to psychiatric disorders associated with alterations in GABAergic transmission (Marin, 2012; Cunha-Rodrigues et al., 2018; Lacaille et al., 2019). A significant reduction of several markers of GABAergic transmission, including glutamic acid decarboxylase (GAD), GABA, GABA $A_{A}$ receptors $\left(G A B A_{A} R s\right)$, and perturbed parvalbumin (PV) and somatostatin (SST) expression in cortical interneurons, have been reported in the neonatal brain after injury (Robinson et al., 2006; Komitova et al., 2013). In addition, postmortem samples from human preterm infants with brain injury, as well as

Received January 7, 2021; accepted January 9, 2021; First published January 25, 2021.

The authors declare no competing financial interests.

Author contributions: E.M.S.G. designed research; K.K., J.F., M.A.A., C.K.-H., and E.M.S.G. performed research; M.G. and J.-M.F. contributed unpublished reagents/analytic tools; K.K., J.F., and E.M.S.G. analyzed data; J.-M.F. and E.M.S.G. wrote the paper.

This work was supported by the University of Zurich and the Swiss National Science Foundation MHV Grant PMPDP3_145480 (to E.M.S.G.) and by the Baugenossenschaft Zurlinden.

${ }^{*}$ K.K. and J.F. contributed equally to this work.

Acknowledgements: We thank Prof. Christian Grimm for scientific feedback, Dr. Lena Rubi and Mohammad Hleihil for their support with electrophysiology, Dr. Tatjana Haenggi for genotyping the animals, Fabio Valeri for his support with statistics, and Barbara Ellis, Dr. Christina Boyle, and Dr. Robert Ganley for proofreading this manuscript.

Correspondence should be addressed to Edith M. Schneider Gasser at edith.schneidergasser@uzh.ch.

https://doi.org/10.1523/ENEURO.0006-21.2021

Copyright @ 2021 Khalid et al.

This is an open-access article distributed under the terms of the Creative Commons Attribution 4.0 International license, which permits unrestricted use, distribution and reproduction in any medium provided that the original work is properly attributed. the hippocampus of rat models of prematurity, showed reduced potassium-chloride co-transporter 2 (KCC2) expression (Jantzie et al., 2014). Perturbations of the GABAergic system in PBI might disrupt the excitatory/inhibitory balance and lead to long-lasting deficits in brain function (Komitova et al., 2013). Therefore, there is an urgent need for new therapeutic strategies protecting the GABAergic system in clinical neonatology.

Erythropoietin (EPO), the erythropoietic hormone (Farrell and Lee, 2004). is a leading therapy in neonatology as a neuroprotective agent (Juul et al., 2015; Juul and Pet, 2015; Natalucci et al., 2016). EPO signaling, leads to activation of several downstream pathways including the STAT5, ERK1/2, and PI3K/Akt pathways (Lombardero et al., 2011). EPO's immediate neuroprotective effects are anti-apoptotic, anti-inflammatory, and anti-oxidative (Noguchi et al., 2007; Rangarajan and Juul, 2014). In the long-term, EPO stimulates angiogenesis (Zhu et al., 2014), neurogenesis (Castaneda-Arellano et al., 2014). and oligodendrogenesis (Jantzie et al., 2013; Juul et al., 2015). EPO has also been shown to restore deficits in KCC2 expression (Jantzie et al., 2014), and enhance synaptic plasticity and cognition (Adamcio et al., 2008; Kamal et al., 2011; Sargin et al., 2011; Almaguer-Melian et al., 2015), while facilitating inhibitory synaptic transmission (Wojtowicz and Mozrzymas, 2008; Roseti et al., 2020). Nevertheless, it is not yet established whether EPO promotes the development of GABAergic neurons and GABAergic neurotransmission.

EPO and its receptor [EPO receptor (EPOR)] are expressed in human and mouse brain (Digicaylioglu et al., 1995; Marti et al., 1996). Specifically, they are reported to be expressed in the embryonic neocortex in areas close 
to ventricles and deeper layers, regulating radial migration and laminar positioning of granular neurons (Constanthin et al., 2020). Here, we report that EPORs are highly expressed postnatally in the cornu ammonis (CA) 1 hippocampus from mice, increasing their expression to reach a zenith toward adulthood. Additionally, we showed in a transgenic mouse line constitutively overexpressing human EPO in the CNS, without hematopoietic changes (Tg21; Wiessner et al., 2001), a strong activation of the AKT pathways in the postnatal CA1 hippocampus (Jacobs, R. A., Aboouf M. A., Laouafa S., Arias-Reyes C., Koester-Hegmann C., Thiersch M., Soliz J., Gassmann M, and Schneider Gasser E.M., Comm biology, unpublished observations). AKT phosphorylation has a strong antiapoptotic action and can increase the number of $\mathrm{GABA}_{\mathrm{A}} \mathrm{Rs}$ on the plasma membrane increasing synaptic transmission in neurons (Wang et al., 2003). Therefore, we hypothesize an important role for EPO signaling in postnatal hippocampal GABAergic maturation.

During the second postnatal week, GABAergic transmission in the CA hippocampus switches from excitatory, because of elevated intracellular chloride concentration, to inhibitory at around postnatal days (P)13-P15 (Tyzio et al., 2007), an age that coincides with a peak in synaptogenesis, and the formation of adult neuronal networks (Ben-Ari et al., 2007). GABAergic transmission is essential for establishing critical periods of enhanced synaptic plasticity during development (Hensch and Bilimoria, 2012). Perineuronal nets (PNNs) are specialized extracellular matrix (ECM) structures composed of chondroitin sulfate proteoglycans that are responsible for synaptic stabilization, a process that influences the closing of critical periods of plasticity. In the hippocampus PNNs are found around the somata and proximal dendrites of PV+ interneurons, with an onset at P8, a time point when the expression of PV increases and also the midpoint in the switch from excitatory to inhibitory GABAergic transmission. PNNs are good indicators of brain maturation and contribute to the maintenance of the excitatory/inhibitory balance (Hensch, 2005; Fowke et al., 2018). Several secreted factors, including neurotrophic factors, also modulate the maturation of inhibitory circuits and consequently the timing of PNN formation (Huang et al., 1999; Begum and Sng, 2017). It remains to be elucidated whether EPO regulates the formation of PNNs.

In this work, we quantified the numbers of interneurons immunoreactive for GABA, PV, SST, and neuropeptide Y (NPY), analyzed the formation of PNNs, evaluated the glutamatergic innervation of $\mathrm{PV}+$ neurons, we quantified the density of GABAergic synapses in the CA1 area and recorded spontaneous IPSC (sIPSC) and miniature IPSC (mIPSC) in pyramidal cells using whole-cell electrophysiology. Finally, we determined, the cellular mRNA expression of EPORs in the CA1 area and evaluated EPORs and PV+ cell numbers in GAD65-cre ${ }^{\mathrm{Tg} /+}$, $E_{P O R}{ }^{f x / f x}$ mice. Our data show that EPO increases postnatal neuronal survival, enhances $G_{A B A} R s$ and conductance onto pyramidal cells; increases glutamatergic inputs onto PV+ cells, and accelerates PNN formation. Thus, EPO is a potential drug to stimulate hippocampal GABAergic maturation without causing any network imbalance.

\section{Materials and Methods}

\section{Animals}

Animal experiments were performed following the ARRIVE guidelines and were approved by the Cantonal Veterinary Office of Zurich, Switzerland. Mice were bred on a C57BL/6 background at the Laboratory Animal Service Centre of the University of Zurich and kept in standard housing conditions with food and water provided ad libitum. At least three animals per genotype and age from three different litters were used for each experiment.

\section{$\operatorname{TgN}(P D G F B-E P O) 322 Z b Z(T g 21)$}

The Tg21 transgenic mouse line overexpressing EPO in the CNS was generated by pronuclear microinjection of the full-length human EPO cDNA driven by the plateletderived growth factor (PDGF) B-chain promoter into fertilized oocytes derived from B6C3 hybrid mice (Ruschitzka et al., 2000; Wiessner et al., 2001). The resulting hemizygous offspring was then backcrossed with C57BL/6 mice and bred to homozygosity to generate transgenic $\mathrm{TgN}$ (PDGFB-EPO)322ZbZ (Tg21) and wild-type (WT) mouse lines with the same genetic background. Experiments were performed in mice of both sexes, and group sizes are reported with the statistical analyses.

\section{GAD65-cre,EPOR ${ }^{f x / f x}$}

Heterozygous GAD65-Cre (kind gift from H. U. Zeilhofer, University of Zurich, Switzerland) male mice were bred with homozygous EPOR floxed (fx) female mice (kind gift from C. Grimm, University of Zurich, Switzerland). Cre-positive, $\mathrm{EPOR}^{\mathrm{fx} /+}$ offspring were bred again with homozygous EPOR floxed mice. Cre-positive, EPOR ${ }^{\mathrm{fx} / \mathrm{fx}}$ offspring was then used for immunostaining and $\mathrm{flSH}$ analysis and compared with Cre-negative, EPOR ${ }^{f / f x}$ mice.

\section{Immunohistochemistry}

Tissue preparation for immunoperoxidase staining

WT and Tg21 mice of both sexes were collected at P7, $\mathrm{P} 11, \mathrm{P} 14, \mathrm{P} 21$, and P60; GAD65-cre-positive, EPOR ${ }^{\mathrm{f} \times / \mathrm{fx}^{\prime}}$ and GAD65-cre-negative, $\mathrm{EPOR}^{\mathrm{fx} / \mathrm{fx}}$ were collected at P11, and anesthetized by intraperitoneal pentobarbital injection (Nembutal: $50 \mathrm{mg} / \mathrm{kg}$; i.p., Kantonsapotheke Zürich). They were then perfused transcardially with PBS $(\mathrm{pH} 7.4)$ to rinse blood, followed by fixative containing $4 \%$ paraformaldehyde in $0.15 \mathrm{~m}$ Na-phosphate buffer, $\mathrm{pH} 7.4$. Brains were immediately dissected, cut sagittal through the midline, and postfixed in the same fixative for $24 \mathrm{~h}$ for $\mathrm{P} 7,18 \mathrm{~h}$ for P11, $12 \mathrm{~h}$ for P14, and $3 \mathrm{~h}$ for P21 and P60 tissue. After postfixation, brains were transferred to $30 \%$ sucrose (in PBS) at $4^{\circ} \mathrm{C}$ for $24-72 \mathrm{~h}$ until tissue sank, for cryoprotection. Brains were cut into sagittal serial sections at $50 \mu \mathrm{m}$ for $\mathrm{P} 7$, and $40-\mu \mathrm{m}$ thickness for other ages using a sliding blade freezing microtome (HM400; Microm). Six serial sections were collected for brains at $P 7$, eight serial sections for $P 11,10$ serial sections for 
Table 1: Primary antibodies used for immunohistochemistry

\begin{tabular}{llllll}
\hline Target & Host species & Dilution & Catalog \# & Company/origin & References \\
\hline$\gamma$-aminobutyric acid (GABA) & Rabbit & $1: 1000$ & A-2052 & Sigma & Dzyubenko et al. (2017) \\
Neuronal nuclei (NeuN) & Mouse monoclonal & $1: 1000$ & MAB377 & Merck & Mullen et al. (1992) \\
PV & Rabbit & $1: 5000$ & PV-28 & SWant & Vaghi et al. (2014) \\
NPY & Rabbit & $1: 1000$ & T-4069 & Peninsula Lab. & Mackay al. (2019) \\
SST & Rabbit & $1: 500$ & sc-13099 & Santa Cruz & Yang et al. (2008) \\
VGAT & Mouse monoclonal & $1: 2000$ & 131011 & Synaptic Systems & Pan-Vazquez et al. (2020) \\
Gephyrin & Rabbit monoclonal & $1: 1000$ & 147008 & Synaptic Systems & Schneider Gasser et al. (2006) \\
GABA R $_{2}$ & Guinea pig & $1: 2000$ & N/A & Home made & Fritschy and Mohler (1995) \\
vGluT1 & Guinea pig & $1: 1000$ & 135304 & Synaptic Systems & Wei et al. (2016) \\
vGluT2 & Guinea pig & $1: 3000$ & AB2251 & Merck & Holló et al. (2017) \\
Cleaved caspase-3 & Rabbit & $1: 200$ & 9661 & Cell Signaling & Teoh et al. (2017) \\
& & & & &
\end{tabular}

P14, and 12 serial sections for P21 and P60. Sections were stored at $-20^{\circ} \mathrm{C}$ in antifreeze solution until use.

\section{Tissue preparation for immunofluorescence}

WT and Tg21 mice of both sexes collected at P11, P14, P21, and P60, were deeply anesthetized with an intraperitoneal injection of sodium pentobarbital $(50 \mathrm{mg} / \mathrm{kg})$, and perfused transcardially at a constant flow rate with 8-12 $\mathrm{ml} / \mathrm{min}$ of ice-cold oxygenated artificial CSF (ACSF), $\mathrm{pH}$ 7.4. Following immediate decapitation, the brain was dissected, cut sagittal through the midline and postfixed in ice-cold 4\% paraformaldehyde (dissolved in $0.15 \mathrm{~m} \mathrm{Na-}$ phosphate buffer, $\mathrm{pH}$ 7.4) $3 \mathrm{~h}$ for P11 and P14 and 90 min for P21 and P60. Brains were then rinsed twice with cold PBS, transferred to $30 \%$ sucrose in PBS for cryopreservation and stored for $3 \mathrm{~d}$ at $4^{\circ} \mathrm{C}$. Brains were frozen with dry ice and kept at $-80^{\circ} \mathrm{C}$ until further use. Sagittal sections were cut as described above.

\section{Immunoperoxidase staining}

PV-immunoreactive, SST-immunoreactive, NPY-immunoreactive, and CB-immunoreactive interneurons in the hippocampus were quantified in sections processed for immunoperoxidase staining. Free-floating sections were washed three times for 10 min each with Tris-Triton buffer, $\mathrm{pH} 7.4$ followed by incubation with rabbit primary antibody against PV (Table 1 ) in a solution containing $2 \%$ Triton X-100 and 2\% normal goat serum (NGS) in TrisTriton buffer, $\mathrm{pH} 7.4$, overnight at $4^{\circ} \mathrm{C}$ under continuous agitation. The next day, the sections were rinsed again three times for 10 min each with Tris-Triton buffer, $\mathrm{pH} 7.4$ before being incubated at room temperature (RT) for $30 \mathrm{~min}$ with the biotinylated secondary antibody (goat anti-rabbit, Jackson ImmunoResearch, 1:300) in a solution containing 2\% NGS in Tris-Triton buffer, $\mathrm{pH}$ 7.4. After another washing step of three times $10 \mathrm{~min}$, the sections were incubated for $30 \mathrm{~min}$ in avidin-biotin complex solution (Vectastain Elite kit; Vector Laboratories) and rinsed again three times for $10 \mathrm{~min}$. To allow equal penetration of the tissue, the sections were preincubated in diaminobenzidine $(\mathrm{DAB})$ solution $(0.5 \times \mathrm{g} / \mathrm{L}$ DAB in Tris-Triton buffer, $\mathrm{pH}$ 7.7) for 5 min under agitation, before the reaction was started by adding $2 \mathrm{ml}$ of DAB solution containing $0.01 \%$ hydrogen peroxidase. After 5-7 min, depending on the intensity of the staining, the reaction was stopped by transferring the sections into ice-cold
PBS followed immediately by another washing step of three times $10 \mathrm{~min}$ in PBS. The sections were mounted on gelatin-coated glass slides and left to dry overnight. On the following day, they were dehydrated in ethanol of increasing concentrations $(2 \times 70 \%, 2 \times 96 \%, 3 \times$ $100 \%$ ) for 5 min each followed by clearing in xylene four times for $5 \mathrm{~min}$. Finally, the sections were cover-slipped with Eukitt mounting medium (Merck).

\section{Immunofluorescence staining}

Double or triple immunofluorescence staining was used to analyze multiple markers within the same section. Free-floating sections were washed three times for $10 \mathrm{~min}$ each in Tris-Triton buffer, $\mathrm{pH} 7.4$ before being incubated overnight at $4^{\circ} \mathrm{C}$ under continuous agitation with the primary antibodies raised in different species (Table 1) in a solution containing $2 \%$ Triton X-100 and $2 \%$ NGS in TrisTriton buffer, $\mathrm{pH}$ 7.4. The next day, the sections were again rinsed three times for $10 \mathrm{~min}$ with Tris-Triton buffer, $\mathrm{pH} 7.4$ followed by incubation with secondary antibodies raised in goat against the different species of the primary antibodies and coupled to either Alexa Fluor 488, Cy3, or Alexa Fluor 647 [or the plant lectin Wisteria floribunda agglutinin (WFA) coupled to Cy3 for staining of PNNs] in a solution containing $0.5 \mu \mathrm{LAPI}$ and $2 \%$ NGS in Tris-Triton buffer, $\mathrm{pH} 7.4$ at RT for 30 min in the dark. After another washing step of three times 10 min with Tris-Triton buffer, $\mathrm{pH} 7.4$, sections were mounted on gelatin-coated glass slides and cover-slipped with Dako fluorescence mounting medium (Dako).

\section{Fluorescence in situ hybridization (fISH)}

Tissue preparation for fISH

WT, Tg21 mice of both sexes at postnatal ages P7, P11, $\mathrm{P} 21$, and P60, and GAD65-cre-positive, EPOR ${ }^{\mathrm{fx} / \mathrm{fx}}$, and GAD65-cre-negative, EPOR ${ }^{\mathrm{fx} / \mathrm{fx}}$ mice at postnatal age $\mathrm{P} 11$, were deeply anesthetized with an intraperitoneal injection of sodium pentobarbital $(50 \mathrm{mg} / \mathrm{kg}$ ) followed by decapitation and dissection of brain tissue on ice. Hemispheres where then frozen on dry ice and stored at $-80^{\circ} \mathrm{C}$ until use. Serial brain sections of $10 \mu \mathrm{m}$ were cut using a cryostat (Leica Biosystems), mounted on Superfrost slides and stored at $-80^{\circ} \mathrm{C}$. 


\section{fISH}

$\mathrm{fISH}$ of murine EPOR (RNAscope Probe-Mm-Epor) was performed, using the RNAscope Multiplex Fluorescent reagent kit v2 from Advanced Cell Diagnostics and the fluorophore Opal 520 from PerkinElmer. Positive and negative control probes (RNAscope 3-plex positive and negative control probes) were always run in parallel.

Fresh frozen tissue was postfixed for $30 \mathrm{~min}$ at $4^{\circ} \mathrm{C}$ in $4 \%$ paraformaldehyde prepared in $0.15 \mathrm{~m} \mathrm{Na-phosphate}$ buffer ( $\mathrm{pH} 7.4)$, treated $10 \mathrm{~min}$ with hydrogen peroxide at $\mathrm{RT}$, target retrieval for $10 \mathrm{~min}$ at $85^{\circ} \mathrm{C}$ (RNAscope Target Retrieval reagent) and protease treatment with Protease Plus for $30 \mathrm{~min}$ at $40^{\circ} \mathrm{C}$. Probes were hybridized for $2 \mathrm{~h}$ at $40^{\circ} \mathrm{C}$. Slides were washed in Tris-Triton buffer, $\mathrm{pH} 7.4$ followed by amplification steps (RNAscope Amp1) and signal development (HRP-C1 + fluorophore 1). Finally, slides were incubated for $3 \mathrm{~min}$ in DAPI and coverslipped.

\section{Image acquisition}

\section{Bright-field microscopy}

Sections processed for immunoperoxidase staining were visualized and photographed with an Axioscope 2 microscope (Carl Zeiss AG) equipped with a color digital camera (AxioCam MRc5) and its corresponding software, AxioVision 4.5 (Carl Zeiss AG). Images of the whole hippocampus were taken with bright-field illumination using a $5 \times$ objective (NA 0.15).

\section{Fluorescence microscopy}

Images of cleaved caspase-3 and DAPI samples were imaged with a Zeiss Axio Imager 2 fluorescent microscope (Carl Zeiss AG). Image stacks (five slices, $2-\mu \mathrm{m}$ intervals) from CA3 and CA1 areas were taken with a $10 \times$ objective, with a scan zoom of $1 \times$ and image size of $1024 \times 1024$ pixels.

\section{Confocal laser-scanning microscopy}

Immunofluorescence GABA and NeuN-stained tissue sections were imaged using a Zeiss LSM 700 confocal laser scanning microscope (Carl Zeiss AG) with a $40 \times$ oil immersion objective with a numerical aperture (NA) of 1.4. Images were taken as $z$-stacks (five slices, $1-\mu \mathrm{m}$ intervals) with a scan zoom of $1 \times$ for CA3 area and $0.5 \times$ for the CA1 area and an image size of $1024 \times 1024$ pixels.

For GABAergic synaptic cluster analysis, vesicular GABA transporter (VGAT), gephyrin and $\mathrm{GABA}_{A} \mathrm{R} \gamma 2$ subunits were stained, and sections were imaged using a Zeiss LSM 800 confocal laser scanning microscope (Carl Zeiss AG). For glutamatergic inputs, vesicular glutamate transporter (vglut)1-2 and PV cells stained sections were imaged. A $63 \times$ oil immersed objective with a NA of 1.4 was used for synapse analysis. Images were taken as $z-$ stacks (five slices, $0.2-\mu \mathrm{m}$ intervals) with a scan zoom of $1.5 \times$ and an image size of $1024 \times 1024$ pixels. Imaging parameters were kept constant over all conditions. After acquisition, images were processed using 2D super resolution Airy Scan processing run in automated mode. image acquisition was conducted in the stratum pyramidale and stratum radiatum of the CA1 and CA3 region.
For analysis of PNNs around PV+ interneurons, double-stained sections were imaged using a Zeiss LSM 800 confocal laser scanning microscope (Carl Zeiss AG) with a 10× objective (NA 0.45) and taking image stacks composed of 22 slices at a $z$-intervals of $0.4 \mu \mathrm{m}$. Image acquisition was performed in the CA1 and the CA3 area of the hippocampus and image settings were kept constant between genotypes within every age.

fISH image acquisition. Samples were imaged with a Zeiss LSM 700 confocal laser scanning microscope (Carl Zeiss AG). Image stacks (six optical sections, 0.5- $\mu \mathrm{m}$ step size) from CA1 and CA3 stratum pyramidale and radiatum were acquired with at $40 \times$ objective, N.A. 1.4.

\section{Stereology}

Unbiased counting of PV + , SST + , and NPY + interneurons in the hippocampus was performed using the $10 \times$ objective (NA 0.45) of an Axioplan 2 bright-field microscope (Carl Zeiss AG) equipped with a digital camera (MicroFIRE, Optronics AG). First, the hippocampal CA1 and CA3 areas containing the different subregions: stratum oriens, stratum pyramidale, stratum radiatum and stratum lacunosum moleculare, were delineated with Mercator Pro software (Explora Nova) according to the mouse brain atlas (Paxinos, 2007). Subsequently, immunoreactive cells were counted in each of these areas with no distinction of subregions. Data collection was done in serial sections throughout the whole hippocampus, analyzed with a serial sampling fraction (ssf) of three for $\mathrm{P} 7$, four for P11, five for P14, and six for P21 and P60. Six animals per genotype and age were analyzed, except for SST analysis where only four animals per genotype were analyzed.

The total volumes $\left(\mathrm{V}_{\mathrm{tot}}\right)$ of the CA1 and CA3 were calculated from the ssf, the areas delineated in every section $\left(A_{i}-A_{n} ; n=\right.$ number of sections analyzed) and the section thickness $(h)$ as follows:

$$
V_{\text {tot }}=s s f \times \sum_{i=1}^{n} A_{i} \times h .
$$

Subsequently, the total number of immuno-positive cells $\left(Q_{\text {tot }}\right)$ in the CA1 and CA3 were calculated using the ssf and the positive cell numbers per section $\left(Q_{i}\right)$ :

$$
Q_{\text {tot }}=s s f \times \sum_{i=1}^{n} Q_{i} .
$$

Total number of $\mathrm{NeuN}+$, and GABA + cells were quantified with the optical Fractionator using the Stereo Investigator software (v10.50, MBF Bioscience) equipped for fluorescence imaging, with a $63 \times$ lens (Zeiss 1.4 Oil). $\mathrm{Neu}+$ and GABA + cells were counted independently in a frame of $40 \times 40 \mu \mathrm{m}$ with a step size of $120 \mu \mathrm{m}$. Total cell numbers $(N)$ were calculated using the formula: $N=\sum Q \cdot\left(\frac{1}{a s f}\right)\left(\frac{1}{s s f}\right)$, where $\sum Q$ is the total number of counted cells, and asf the area sampling factor. A mean of 200 cells was counted per animal. For more details on stereological estimates (Slomianka and West, 2005). 


\section{Optical density analysis}

PV immunoperoxidase staining intensity was assessed by densitometry analysis using the MCID software (MCID Elite 6.0, InterFocus Imaging Ltd.). Images were digitzed using a precision illuminator (Northern Light Model B95, Imaging Research Inc., Brock University, St. Catharines, Canada) and CoolSNAP cf. photo-camera (Photometrics) with a Micro-Nikkor (55+12 mm) objective (Nikon Corp.). Next, a gray value calibration (Kodak step tablet no. 310ST607) was performed, and the intensity was measured in the different regions of interest (ROIs). To correct for variations in background staining, the intensity value was normalized to the intensity of the corpus callosum. A total of five images per animal and three animals per genotype, were analyzed.

\section{Caspase- 3 analysis}

Four brain sections were imaged per mouse and maximum intensity projections were created from $z$-stacks. Cell densities of caspase-3+ cells were directly quantified from each field of view. All imaging parameters were kept constant between groups. Images were processed with Fiji ImageJ (NIH).

\section{PNN analysis}

Raw confocal images were preprocessed to 8-bit grayscale tiff files, before being z-projected into a sum slices image using Image $(\mathrm{NIH})$ software, allowing the image to be analyzed in two dimensions without losing any information. In a next step, PV + cells and PNN number, size and area were analyzed using the Perineuronal net Intensity Program for the Standardization and Quantification of ECM Analysis (PIPSQUEAK) macro (Slaker et al., 2016) in FIJ (ImageJ, NIH) software. The macro was run in semi-automated mode, which allowed the manual confirmation of $\mathrm{PV}+$ cells and PNNs. Background subtraction was achieved with Rolling Ball Radius followed by the selection of 20 ROls around the perimeter of an image. After removal of high and low outlier ROls, a mean background value could be calculated to remove variability in background staining (Slaker et al., 2016). Analysis of PV and PNN fluorescence intensity was performed in average projection images from $z$-stacks using a custom-made macro in Image $J$ $(\mathrm{NIH})$ software. Processing of both channels included thresholding method Yen for PNN and Otsu for PV, background subtraction, Gaussian blurring, and size restrictions. Six animals per age and genotype were used for the analysis. Data points represent average values of the total quantified cells per animal.

\section{Synaptic cluster analysis}

Morphologic quantification of synaptic cluster densities was performed in maximal intensity projection images from three images in the $z$-stack, using a custom-made macro in ImageJ software (NIH). Processing of all channels included background subtraction with Rolling Ball Radius, Gaussian blurring, thresholding for selecting ROls of high staining intensity (representing local accumulation of synaptic proteins), as well as shape (circularity: 0.4-1) and size (minimal area $0.1 \mu \mathrm{m}^{2}$ ) restrictions for cluster detection, using the same parameters in all images per genotype and age. GABAergic synapses were detected based on colocalization of a $\gamma_{2}-G_{A B A} R$, gephyrin, and VGAT-immunofluorescence. vGlut1-2 inputs onto PV+ cells were quantified by colocalization of both channels. To determine apposition of presynaptic markers (vGAT and vGluT), the size of the cluster was increased by one pixel all around (Tyagarajan et al., 2011; Früh et al., 2016). Four mice per genotype and age were used for the analysis.

\section{fISH analysis}

Analysis was done in z-stack images with maximum intensity projection, using a custom-made cluster analysis macro in Image $(\mathrm{NIH})$ software. Processing of EPOR particles (green channel) was separately analyzed, with background subtraction using rolling ball radius, Gaussian blurring, and thresholding for selecting ROls of high staining intensity, as well as shape (0.5-1 circularity) and size $(0.1-1 \mu \mathrm{m}$ in diameter) restrictions. The same parameters were used in all images per genotype and age. Six animals were used for the analysis.

\section{Electrophysiology \\ Acute brain slice preparation}

WT and Tg21 in the postnatal age ranges of P13-P15 and P19-P22 were briefly anaesthetized with isoflurane and decapitated. The number of recordings for each group are as follows; at P13-P15, WT $n_{\text {(cells) }}=8, n_{\text {(animals) }}=4$ and for Tg21 $n_{\text {(cells) }}=9, n_{\text {(animals) }}=5$; at P19-P22, WT $n_{\text {(cells) }}=8$, $n_{\text {(animals) }}=6$ and for Tg21 $n_{\text {(cells) }}=8, n_{\text {(animals) }}=6$. The brain was quickly removed and transferred to ice-cold dissection solution containing $65 \mathrm{~mm} \mathrm{NaCl}, 2.5 \mathrm{~mm} \mathrm{KCl}, 1.25 \mathrm{~mm}$ $\mathrm{NaH}_{2} \mathrm{PO}_{4}, 25 \mathrm{~mm} \mathrm{NaHCO} 3,7 \mathrm{~mm} \mathrm{MgCl}, 0.5 \mathrm{~mm} \mathrm{CaCl}_{2}, 25$ $\mathrm{mm}$ glucose and $105 \mathrm{~mm}$ sucrose, saturated with $95 \% \mathrm{O}_{2}$ and $5 \% \mathrm{CO}_{2} .350 \mu \mathrm{m}$-thick sagittal slices containing the hippocampus were cut from the tissue block with a vibratome (Leica) and kept in oxygenated ACSF (315 mOsm) containing $125 \mathrm{~mm} \mathrm{NaCl}, 2.5 \mathrm{~mm} \mathrm{KCl}, 1.25 \mathrm{~mm} \mathrm{NaH}_{2} \mathrm{PO}_{4}$, $25 \mathrm{~mm} \mathrm{NaHCO}_{3}, 1 \mathrm{~mm} \mathrm{MgCl}_{2}, 2 \mathrm{~mm} \mathrm{CaCl}_{2}$, and $25 \mathrm{~mm}$ glucose at $32^{\circ} \mathrm{C}$ for $25 \mathrm{~min}$ and then at RT until use.

\section{Whole-cell recordings}

For recording, individual slices were transferred to a recording chamber perfused with oxygenated ACSF (as aforementioned) at a flow rate of 1-2 $\mathrm{ml} / \mathrm{min}$ at RT (21$23^{\circ} \mathrm{C}$ ). Whole-cell patch clamp recordings were made from hippocampal CA1 pyramidal neurons visualized using differential interference contrast (DIC) with an upright microscope (Axioscope, Examiner.A1, Carl Zeiss) at a low, 10× (water immersion objective) magnification; high, 63× (water immersion objective) magnification was used for approaching the cell and achieving a high-resistance (gigaohm) seal. sIPSCs were recorded from CA1 pyramidal cells, clamped at a holding potential of $-70 \mathrm{mV}$, in the presence of $20 \mu \mathrm{m} \mathrm{NBQX}, 50 \mu \mathrm{M} \mathrm{AP}-5$ and $0.5 \mu \mathrm{m}$ Strychnine to block glutamatergic and glycinergic transmission. For mIPSCs, $1 \mu \mathrm{m}$ tetrodotoxin (TTX) was further added to block events caused by action potentials firings. Recordings with an unstable baseline or a holding current 
greater than $-120 \mathrm{pA}$ were rejected. Recording pipettes were made from borosilicate glass (1.5-1.8 O.D., $0.2 \mathrm{~mm}$ thick, Kimble), pulled with a vertical puller (Narishige PC-10), had resistances of 7-9 M $\Omega$ when immersed in ACSF and filled with internal solution containing the following: $130 \mathrm{~mm}$ K-gluconate, $5 \mathrm{~mm} \mathrm{NaCl}, 10 \mathrm{~mm}$ HEPES, 1 mm EGTA, $5 \mathrm{~mm}$ Mg-ATP, and 0.5 mM Na-GTP; pH 7.4, 290-300 mOsm. sIPSCs and mIPSCs were recorded with an internal solution containing the following: $120 \mathrm{~mm} \mathrm{CsCl}, 4 \mathrm{~mm} \mathrm{MgCl} 2,10 \mathrm{~mm}$ HEPES, $10 \mathrm{~mm}$ EGTA, 2 mм Mg-ATP, and $0.5 \mathrm{~mm} \mathrm{Na}-\mathrm{GTP}$; $\mathrm{pH} 7.4,290-310$ mOsm. Recordings were performed using Multiclamp 700B amplifier (Molecular Devices), data were digitized with Digidata 1440A (Molecular Devices) and acquired with the acquisition software Clampex 10.0 (Molecular Devices). All experiments were performed at RT $\left(21-23^{\circ} \mathrm{C}\right)$.

sIPSCs and mIPSCs currents were filtered off-line using a Butterworth low-pass filter $(2 \mathrm{kHz})$, digitized at $10 \mathrm{kHz}$ and analyzed as 2-min epochs following the addition of the pharmacological blockers for $2 \mathrm{~min}$, using the Mini-Analysis Program 6.0.7 (Synaptosoft,). Recordings with leak increasing $>120 \mathrm{pA}$ and access resistance changing $>30 \%$ between the beginning and the end of the recording were discarded. At least 200 events were analyzed for any condition in all experiments. Synaptic events were identified by setting the event detection threshold at least 2-fold higher than the baseline noise level and by ensuring that events had (1) rise times faster than the decay time, (2) rise times $>0.5 \mathrm{~ms}$, and (3) decay times $>1.5 \mathrm{~ms}$; only events adhering to these parameters were included in further analysis. Event amplitudes, interevent intervals, rise and decay times were averaged within each experiment. The frequencies were calculated from the interevent intervals and the resulting means were averaged between experiments.

\section{Statistical analyses}

All statistical analyses were performed using GraphPad Prism 8 (GraphPad Software). Parametric data with two conditions were analyzed using an unpaired, two-tailed Student's $t$ test. Data in different brain areas that were influenced by one factor were analyzed with multiple $t$ test. To compare data influenced by two factors, a two-way ANOVA with Bonferroni multiple comparisons post hoc test was used. Probability distributions were tested using the Kolmogorov-Smirnov (KS) test. For all statistical tests, $p<0.05$ was considered statistically significant. Data are presented as mean \pm SD. In order to confirm appropriate sample sizes for experiments, a Power Analysis was conducted using $G^{*}$ Power software (Heinrich Heine Universität, Düsseldorf, Germany; Faul et al., 2007). Changes in total PV number across ages was evaluated in $\mathrm{R}$ program with a square root curve polyfit (yp = sqrt" number + age + genotype) and the interference value was evaluated with grofit.

\section{Results}

\section{Increased number of GABA-immunoreactive neurons in the hippocampus from $\mathrm{Tg} 21$ mice}

To determine whether constitutive overexpression of human EPO in the CNS influences GABAergic neurotransmission in the hippocampus, the total number of neurons (immunoreactive for NeuN) and the total number of GABA-immunoreactive neurons were stereologically quantified together in the $\mathrm{CA} 3$ and $\mathrm{CA} 1$ regions of Tg21 mice at P7, P14, P21, and P60 and compared with the WT control mice (Fig. 1A,B). Representative images of the CA3 and CA1 areas double-stained for NeuN and GABA at P21 are shown in Figure $1 A$. A significant effect of age and genotype was observed for NeuN-positive cells in the CA area, with increased numbers in Tg21 mice at P21 and P60 (two-way ANOVA, $F_{(1,40)}=16.3$, $p=0.0002$; Fig. $1 B$, upper graph). Likewise, the number of GABAergic neurons was higher in the Tg21 mice starting at P14 (two-way ANOVA, $F_{(1,40)}=77.90, p<0.0001$; Fig. $1 B$, middle graph). The early increase of GABA immunoreactivity resulted in a significantly higher ratio of GABA cells in Tg21 mice at P14 (two-way ANOVA, $F_{(1,40)}=16.53, p=0.0002$; Fig. $1 B$, lower graph).

To determine whether this early increase of GABA immunoreactivity at P14 occurs in specific subpopulations of interneurons, we quantified the total number of $\mathrm{PV}+$, $\mathrm{SST}+$, and NPY + , interneurons in CA1 and CA3 at this age (Fig. $1 C, D$ ). The results showed region-specific differences, being the increased number of GABAergic neurons in CA3 mainly because of an increase in PV + and $\mathrm{NPY}+$ cells (multiple $t$ test, $p=0.024$ and $p=0.044$, respectively; Fig. $1 D$ ), whereas in CA1 mainly because of SST + and NPY + cells (multiple $t$ test, $p=0.005$ and $p=0.018$, respectively; Fig. $1 D$ ). These findings indicate that EPO overexpression accelerates maturation of interneuron subpopulations in a region-specific manner during postnatal development.

\section{Early onset of PV expression in the hippocampus from Tg21 mice}

Given the importance of PV + cells for the regulation of pyramidal cell activity and synchronization during postnatal development, we further explored the effect of EPO on $\mathrm{PV}+$ cell numbers, focusing on the CA1 and CA3 areas at P7, P11, P14, P21, and P26 (Fig. 2). These time points were selected because PV immunoreactivity in the mouse hippocampus appears between P4-P7 and peaks between P14 and P21 (Solbach and Celio, 1991). Quantification of immunolabeled PV cells revealed a highly significant age effect in $\mathrm{CA} 3$ and $\mathrm{CA} 1$ regions, along with a genotype effect in CA3, strongest at P7, where PV + cells were still absent in most WT mice but already expressed in all Tg21 mice (multiple $t$ test, $p=0.007$; Fig. $2 B$ ). Also, at P11 PV + cells were increased in number in CA3 (multiple $t$ test, $p=0.046$; Fig. $2 B$ ). Normalization and analysis [Poly fit (yp $=\operatorname{sqrt}(10)$, $y, 1)]$ of PV cells across development showed a significant increase in PV+ cells at P7, 11 and 14 in CA3 (grofit analysis, $p=0.0003$; Fig. $2 C$ ). Interestingly, not only was the number of PV + cells higher in the CA3 area at P7, P11, and $\mathrm{P} 14$, but the neuropil was also more intensely stained including at P21, as illustrated in Figure $2 A$ and measured by optical density (two-way ANOVA, $F_{(1,50)}=32.43, p<0.0001$; Fig. $2 D)$. In the CA1 area a higher PV staining intensity was 
A

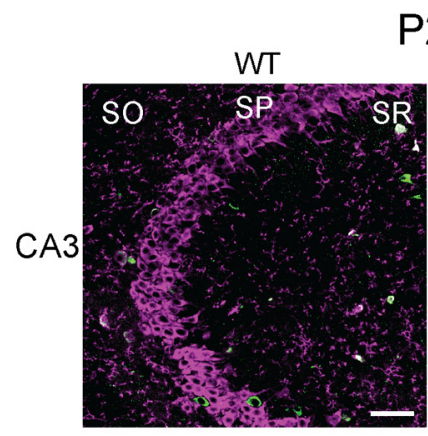

P21
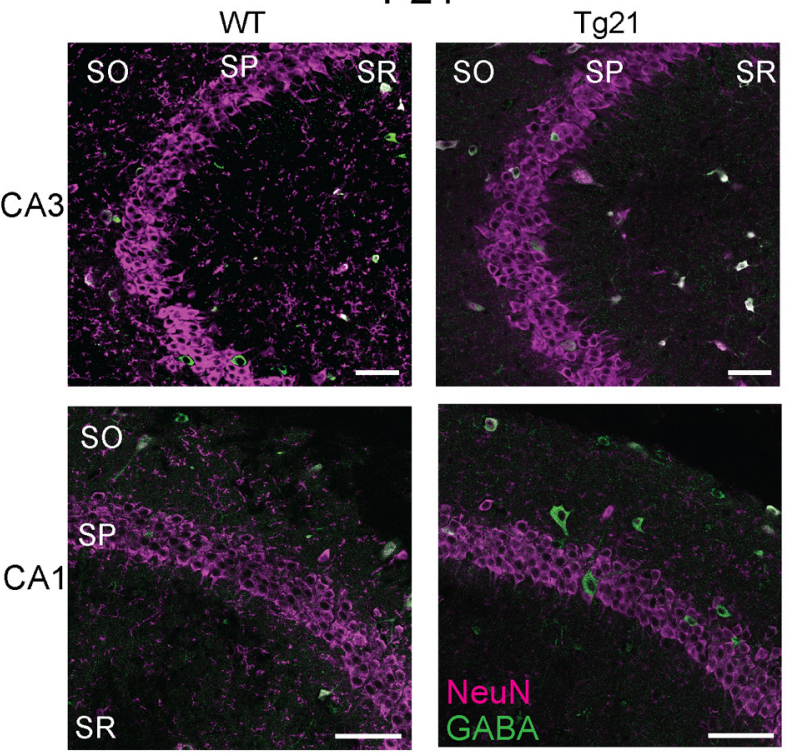

C
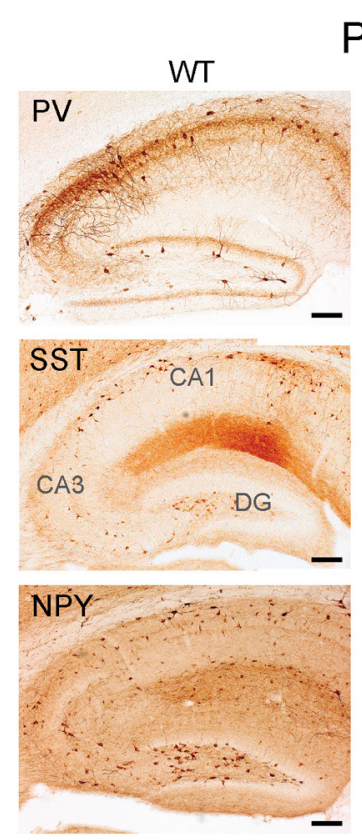

P14
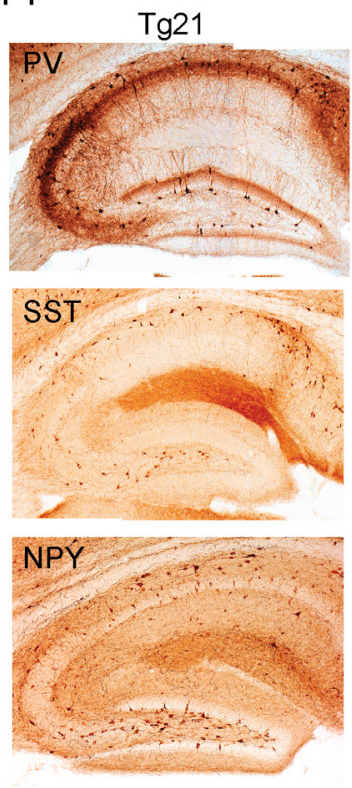

B
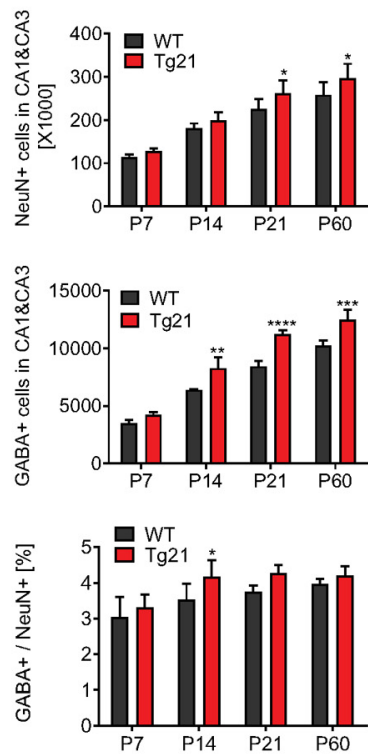

D
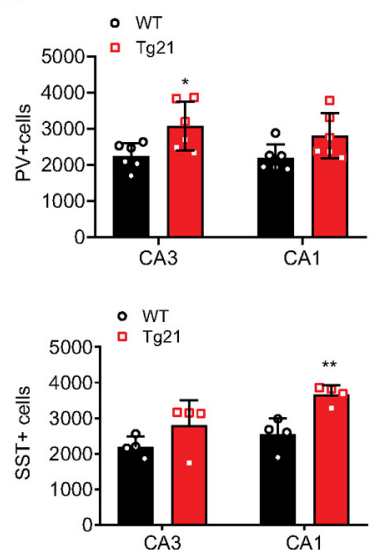

- WT

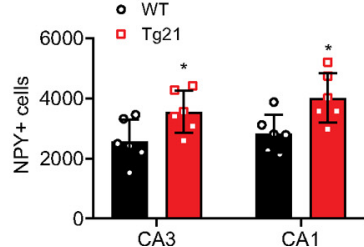

Figure 1. Increased number of GABA-immunoreactive neurons in the hippocampus from Tg21 mice. $\boldsymbol{A}$, Representative images of double immunofluorescence staining against GABA (green) and NeuN (magenta) for CA3 and CA1 areas of WT and Tg21 mice at P21. so: stratum oriens, sp: stratum pyramidale, sr: stratum radiatum. $B$, Unbiased quantification of $\mathrm{NeuN}+$ (upper graph) and GABA+ (middle graph) cells in total CA3 and CA1 area of WT and Tg21 mice, showing age-specific differences between genotypes. Ratio of GABA+/NeuN + cells (lower graph) in WT and Tg21 mice, shows a significant increase of GABA + cells at P14. Data are given as mean \pm SD of total neuronal numbers in the CA1 and CA3 area of the hippocampus; $N=6$ animals per age and genotype. Two-way ANOVA test, ${ }^{*} p<0.05,{ }^{* *} p<0.01,{ }^{* * *} p<0.001,{ }^{* * * *} p<0.0001$. Scale bar: $50 \mu \mathrm{m}$. C, Representative images of PV+, SST+, and NPY + immunoperoxidase staining in hippocampus of WT and Tg21 mice at P14 illustrate the stronger immunoreactivity in PV, SST, and NPY in Tg21 mice. DG: dentate gyrus. $\boldsymbol{D}$, Unbiased quantification of the total cell numbers in CA3 and CA1 areas, revealing increased numbers of PV + cell in CA3, increased number of SST + cells in CA1, and increased number of NPY + cells in CA3 and CA1 in Tg21 mice. Data are given as mean \pm SD, $N=6$ animals per genotype for PV and NPY and $N=4$ animals per genotype for SST staining. Multiple $t$ test; ${ }^{*} p<0.05$, ${ }^{* *} p<0.01$. Scale bar: $200 \mu \mathrm{m}$. 
A

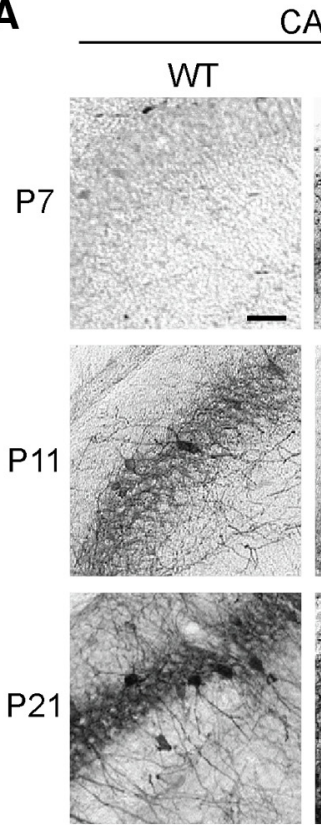

$\mathrm{CA} 3$

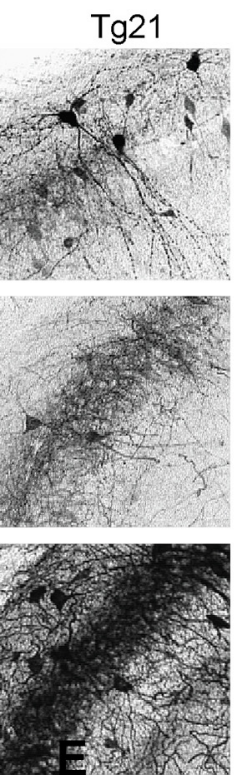

CA1

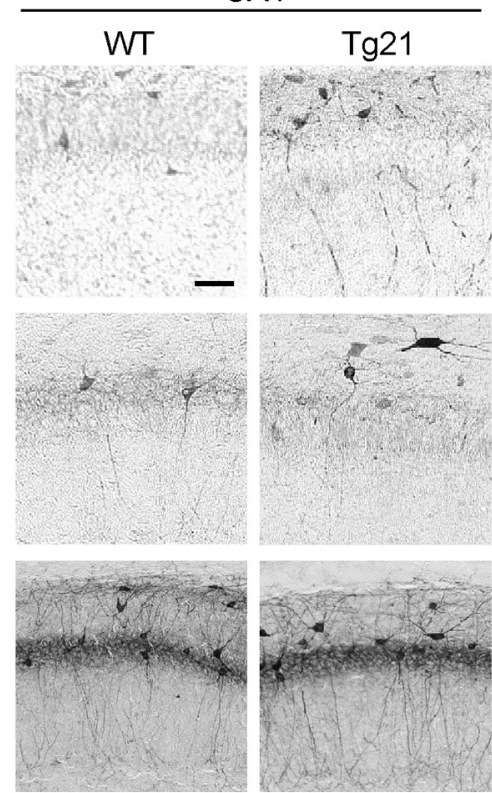

B
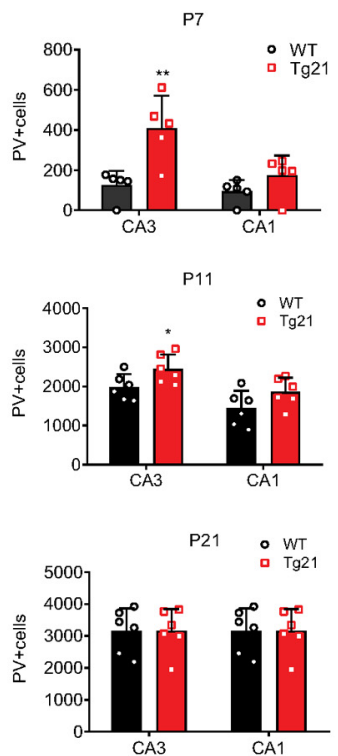

C

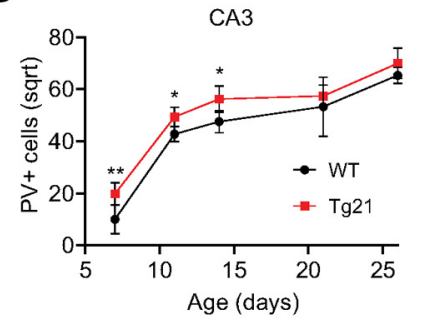

D

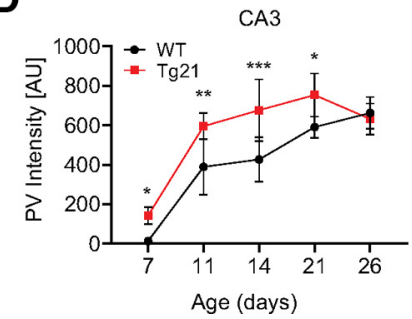

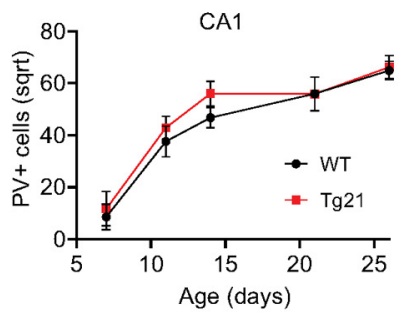

E

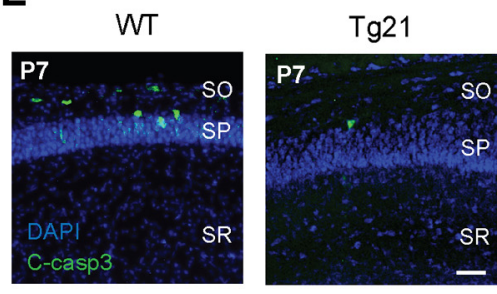

F

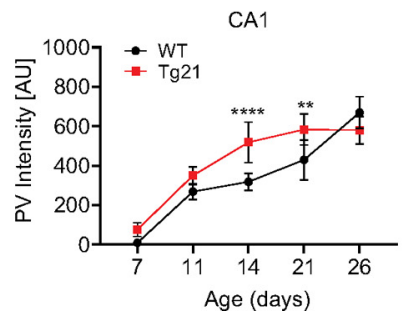

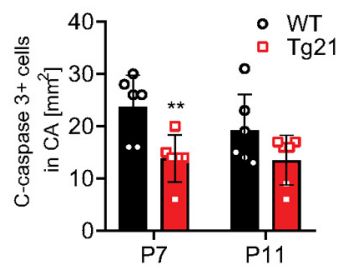

Figure 2. Early onset of PV expression in the hippocampus from Tg21 mice. $\boldsymbol{A}$, Representative images of PV immunoperoxidase staining in CA3 and CA1 areas of WT and Tg21 mice at P7, P11, and P21. Note the earlier appearance of PV + cells in the CA3 area (P7). Scale bar: $50 \mu \mathrm{m}$. B, Unbiased quantification of the total PV + cell numbers at each represented postnatal time point for WT and Tg21 mice. Multiple $t$ test; ${ }^{*} p<0.05,{ }^{* *} p<0.01$. $\boldsymbol{C}$, Significant differences in PV+ cell numbers between genotypes occur in CA3 area at P7, P11, and P14. Grofit interference analysis, ${ }^{*} p<0.05,{ }^{* *} p<0.01$. $\boldsymbol{D}$, Significant difference in PV + intensity is to observe in the CA3 area at postnatal ages: $7,11,14$, and 21 ; and in the CA1 area at postnatal ages: 14 and 21 . Data are given as scatter dot plots and mean $\pm \mathrm{SD}, N=6$ animals per genotype. Two-way ANOVA test; ${ }^{\star} p<0.05,{ }^{\star *} p<0.01,{ }^{\star \star *} p<0.001,{ }^{* \star * *} p<0.0001$. $\boldsymbol{E}$, Representative images of cleaved caspase-3 (green) and DAPI (blue) staining in CA1 areas of WT and Tg21 mice at P7. Scale bar: $50 \mu \mathrm{m}$. F, Cleaved caspase-3 quantification in WT and Tg21in CA3 and CA1 area at P7 and P11. A significant reduction in apoptosis at P7 is observed in Tg21 mice. Two-way ANOVA; ${ }^{*} p<0.05$.

measured at P14 and P21 (two-way ANOVA, $F_{(1,48)}=21.29$, $p<0.0001$; Fig. 2D).

Taken together, our results point to an accelerated maturation of GABAergic neurons in the hippocampus, along with a neurotrophic effect resulting in higher numbers of all neurons persisting until reaching adulthood in Tg21 mice.
Because EPO is an antiapoptotic cytokine (Ghezzi and Brines, 2004) and many interneurons undergo programmed apoptosis early in postnatal development (Southwell et al., 2012; Priya et al., 2018), we analyzed apoptosis in the CA1 and CA3 areas at postnatal ages P7 and P11 (Fig. 2E,F). A reduction in cleaved caspase-3+ cells was observed in the stratum pyramidale and stratum oriens at P7 in Tg21 mice 
(two-way ANOVA, $F_{(1,20)}=11.29, p=0.003$; Fig. $2 E, F$ ). Thus, EPO promotes survival of neurons at the second postnatal week.

\section{EPO influences PNN formation around PV + cells in the hippocampal CA1 and CA3 areas}

To determine whether EPO increases PV+ cell maturation and synapse stabilization, we evaluated the formation of PNNs around PV+ cells, at P7, P11, P14, P21, and P26 in Tg21 and WT mice. The plant lectin WFA, which selectively binds to ECM glycoproteins in the PNNs, was visualized together with PV immunofluorescence (Fig. 3). The following parameters were evaluated in CA1 and CA3 areas: total number of PV+ cells surrounded by PNNs (Fig. 3B), WFA fluorescence intensity (Fig. 3C), PV fluorescence intensity (Fig. $3 D$ ), correlation between PV and WFA intensity at P11 (Fig. 3E). Additionally, soma size and PV intensity were compared between PV+ cells surrounded or not by PNN at P11 (Fig. 3F,G). No genotype effect was observed in number of PV + /WFA+ cells (Fig. $3 B$ ). However, the intensity of WFA was significantly higher in Tg21 mice in CA3 and CA1 areas at P11, and in CA1 at P14 (CA3: two-way ANOVA, $F_{(1,50)}=8.71, p=0.0048$ and CA1: two-way ANOVA, $F_{(1,50)}=18.36, p<0.0001$; Fig. $3 C$ ). Also, PV intensity of WFA surrounded cells was higher in CA3 and CA1 at P11 (CA3: two-way ANOVA, $F_{(1,50)}=3.8, \quad p=0.049$ and CA1: two-way ANOVA, $F_{(1,50)}=3.78, p=0.049$; Fig. $\left.3 D\right)$, which suggest that constitutive EPO overexpression modulates the formation of PNNs at this early stage of development. Since quantification of PV + cells surrounded by PNNs (i.e., WFA + ) showed similar values in the CA3 and CA1 areas, the increased cell numbers at P7, P11 and P14 in CA3 from Tg21 mice reflects uncovered (i.e., WFA-) cells. At P11, a positive correlation between PV and WFA fluorescence intensity was seen in both genotypes [Pearson correlation analysis $(r), p<0.01$; Fig. $3 E$. Also the soma size of $P V+/$ WFA + cells was significantly larger for both genotypes in the CA3 and CA1 areas (CA3, two-way ANOVA, $F_{(1,20)}=8$, $p=0.01$; CA1, two-way ANOVA, $F_{(1,20)}=25.26$, $p<0.0001$; Fig. 3F) and even larger in the Tg21 mice than WT in the CA1 area (CA1, two-way ANOVA, $F_{(1,20)}=$ 4.893, $p=0.0388$; Fig. $3 F$ ). A comparison of PV fluorescence intensity of PV+/WFA- and PV+/WFA+ cells showed that interneurons surrounded by PNNs have a significantly higher PV staining intensity than PV + MFAcells in both genotypes (CA3, two-way ANOVA, $F_{(1,20)}=$ 9.814, $p=0.0052$; CA1, two-way ANOVA, $F_{(1,20)}=21.7$, $p=0.0002$; Fig. $3 G$ ), likewise with a significant genotype effect in the CA1 area, with PV+MFA+ cells in Tg21 mice being more strongly fluorescent than in WT (CA1, two-way ANOVA, $F_{(1,20)}=5.342, p=0.037$; Fig. $\left.3 G\right)$. In brief, our data show that EPO increases the number of PV + MFA- cells during the first two postnatal weeks and accelerates PNN formation at specific early postnatal development windows.

\section{Increased $\mathrm{GABA}_{\mathrm{A}} \mathrm{R}$ cluster density in CA1 pyramidal cells of Tg21 mice at P14}

Next, we examined morphologically, whether the density of GABAergic synapses is affected in Tg21 mice. We studied both perisomatic synapses (primarily formed by $\mathrm{PV}+$ basket cells) in the CA1 stratum pyamidale and dendritic synapses in the CA1 stratum radiatum at P14, P21, and P60. Synapses were identified by triple immunofluorescence staining for the VGAT as a marker of presynaptic terminals, the GABA ${ }_{A} R \gamma_{2}$-subunit, which is ubiquitous in GABAergic postsynaptic densities, and the scaffolding protein gephyrin, which closely interacts with $G_{A B A} R s$ (Fig. 4).

Colocalization of these three markers in puncta (clusters) detected by confocal laser scanning microscopy was considered to represent individual GABAergic synapses, which were quantified accordingly. At P14, a 2fold increase in cluster density was observed in the Tg21 mice as compared with WT ( $t$ test, $p=0.0105$; Fig. $4 E$ ). At later developmental time points $\mathrm{P} 21$ and $\mathrm{P} 60$, no differences were detected between genotypes (Fig. $4 F$, $G)$. We observed that at P14 all individual markers (Fig. $4 B-D)$ were increased in the same proportion $(\sim 20-$ $30 \%$ ) in Tg21 mice (Fig. 4B-D, left column, $C, t$ test, $p=0.047, D, t$ test, $p=0.0050$ ), although VGAT staining did not reach statistical significance ( $t$ test, $p=0.1507$; Fig.4B).

Assessing the size of VGAT+ puncta, representing presynaptic terminals, and $\mathrm{GABA}_{A} \mathrm{R} \gamma 2$ /gephyrin postsynaptic clusters, by cumulative frequency analysis (Tyagarajan et al., 2011), we observed a significant increase for all three markers at P14 (KS test, $p<0.0001$; Fig. $4 B-D$, right column), suggesting that EPO influences both the size of presynaptic terminals and the aggregation of $\mathrm{GABA}_{A} \mathrm{Rs}$ at postsynaptic sites. These results indicate that EPO increases the formation of GABAergic synapses at the soma and proximal dendrites of CA1 pyramidal cells. Our data corroborates what was previously observed in the formation of PNNs, that EPO accelerates the maturation of the GABAergic system.

We also analyzed EPO's impact on the density of GABAergic synapses in pyramidal cells and interneuron dendrites in the stratum radiatum of the CA1 area. In contrast to our observations in the stratum pyramidale, no significant difference in GABAergic synaptic clusters was detected (data not shown), suggesting that EPO mainly affects GABAergic synapses from PV interneurons which occur preferentially on the soma and proximal dendrites of pyramidal cells.

\section{Enhancement of GABAergic synaptic transmission in CA1 area of Tg21 mice at P13-P15}

The increase in synaptic GABAergic markers in CA1 pyramidal cells at $\mathrm{P} 14$ raised the possibility that this morphologic change has a functional correlate. We measured SIPSCs and action potential-independent miniature (mIPSCs). Since we obtained very similar findings for both populations of IPSCs, only the results from the mIPSC analysis are presented here (Fig. 5).

In pyramidal cells recorded in acute hippocampal slices of WT and Tg21 mice at P13-P15, mIPSC baseline noise of WT and Tg21 animals was in average $2 \mathrm{pA}$. Tg21 
A

\section{P11}

CA3
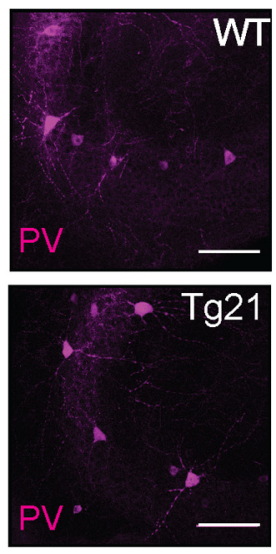
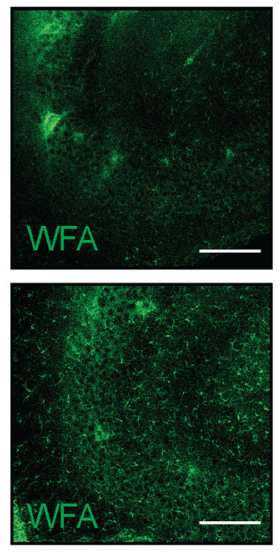
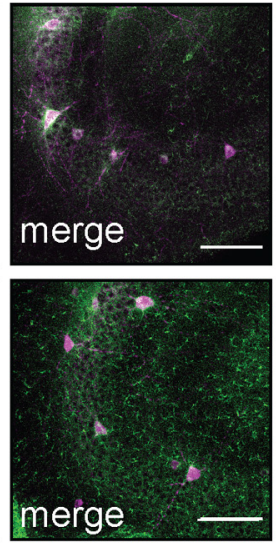

B

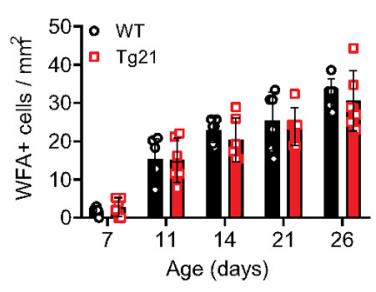

C

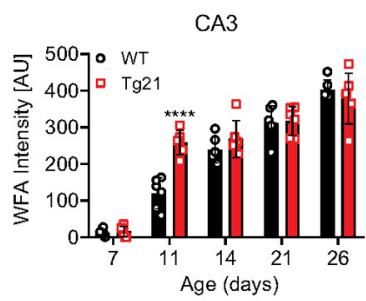

D

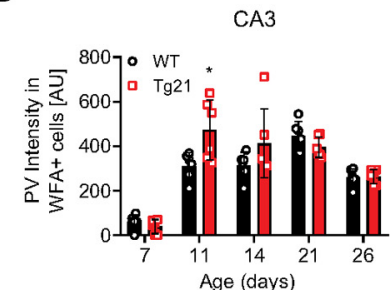

CA1

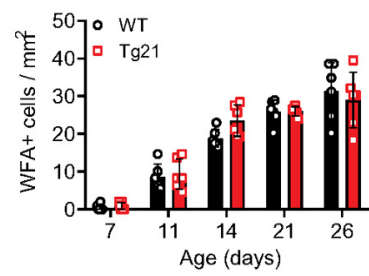

GA1

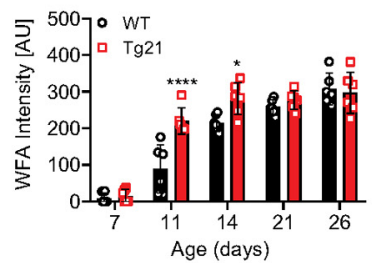

CA1

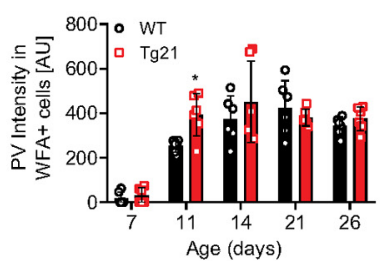

E

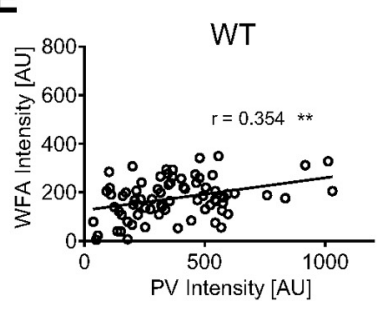

P11
$\mathbf{F}$

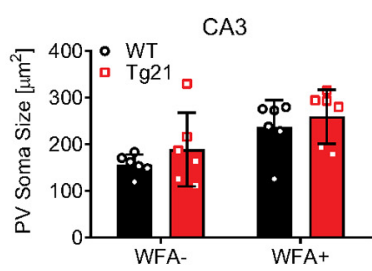

G

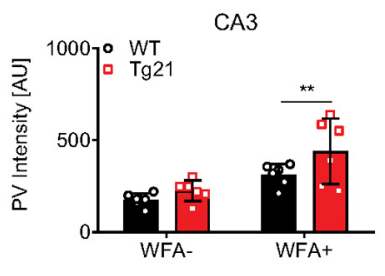

CA1
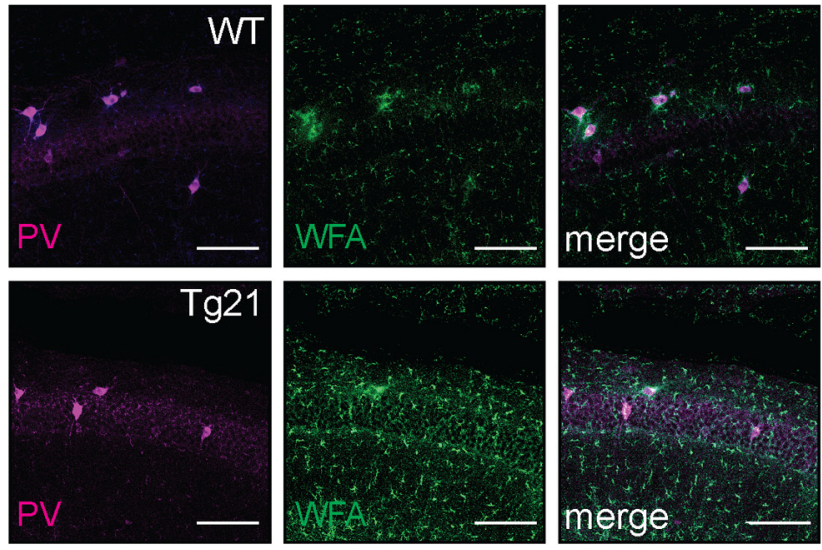

merge

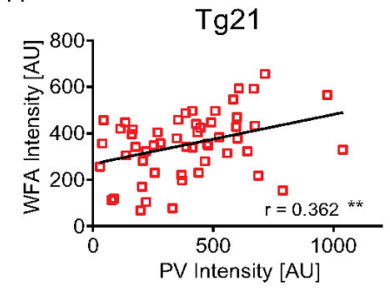

P11

CA1
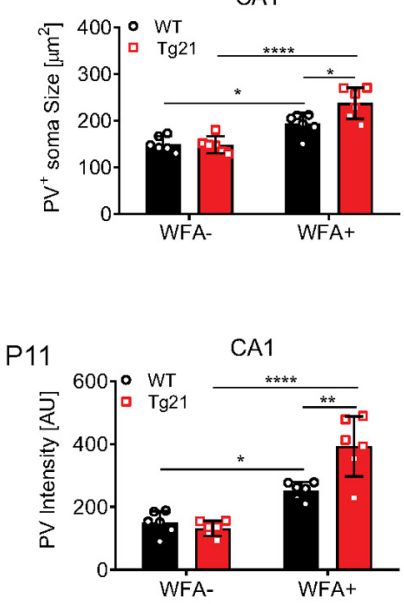

Figure 3. EPO influences PNN formation around PV+ cells in the hippocampal CA1 and CA3 areas. A, Representative images of double labeling for PV immunoreactivity (magenta) and WFA fluorescence that identify PNNs (green) and merged images in CA3 and CA1 areas at P11. Scale bar: $100 \mu \mathrm{m}$. B, Quantification of PV+ cells surrounded by PNN (WFA+) in CA3 and CA1 across postnatal ages. No increase in WFA + cells nor change in the onset is observed between genotypes. $\boldsymbol{C}$, WFA intensity in CA3 and CA1 across postnatal ages. WFA fluorescence intensity is stronger in Tg21 mice CA3 area at P11 and in CA1 area at P11 and P14. D, PV intensity in WFA + cells in CA3 and CA1 area across postnatal ages. PV intensity is stronger in CA3 and CA1 areas at P11 in Tg21 mice. $\boldsymbol{E}$, Correlation analysis of PV and WFA fluorescence intensity in WT and Tg21 mice CA1 area at P11. r: Pearson correlation. $\boldsymbol{F}$, $\mathrm{PV}+$ cells soma size at P11. PV + cells covered by WFA have larger cell somas in CA3 and CA1 area from WT and Tg21 mice. WFA+/PV + cells are larger in Tg21 mice CA1 area. G, PV immunofluorescence intensity at P11. PV intensity is stronger in WFA+ cells, and the intensity is even higher in Tg21 mice in CA3 and CA1 areas. Graphs $(\boldsymbol{B}-\boldsymbol{F})$ show scatter dot plots and mean bars \pm $\mathrm{SD}, N=6$ animals per age and genotype. Two-way ANOVA; ${ }^{*} p<0.05,{ }^{* *} p<0.01,{ }^{* \star *} p<0.001,{ }^{* \star *} p<0.0001$. 
A
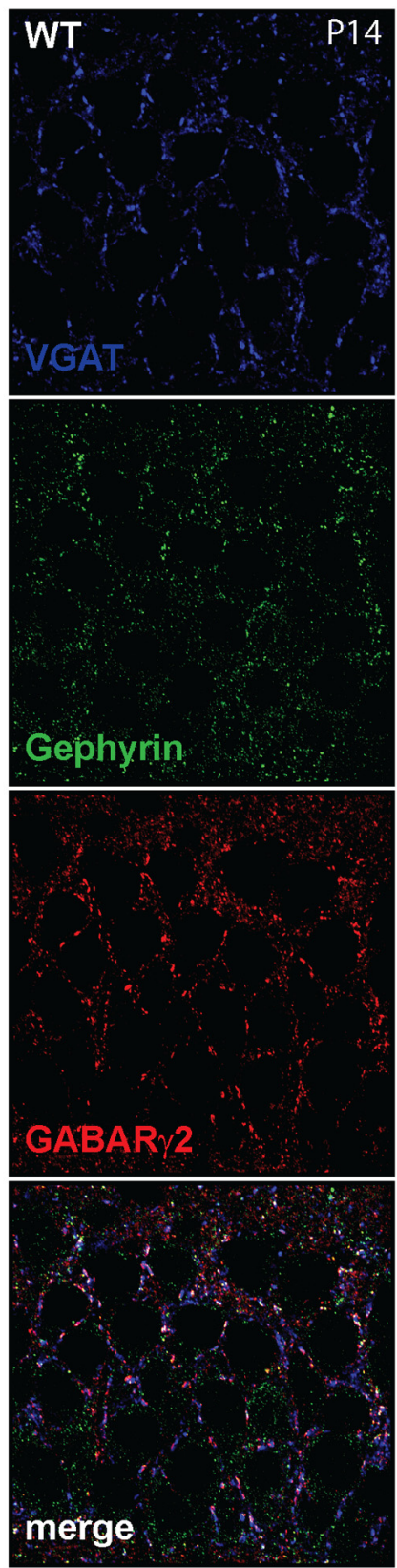
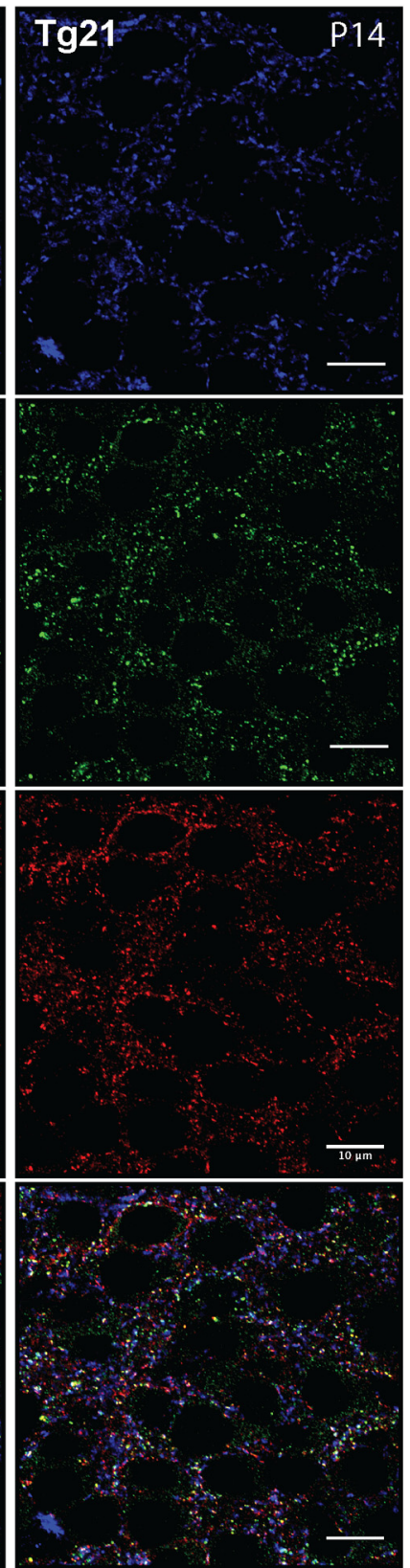

B
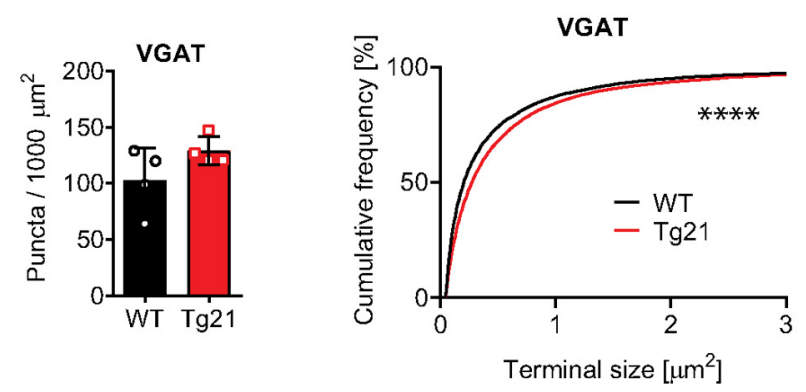

C

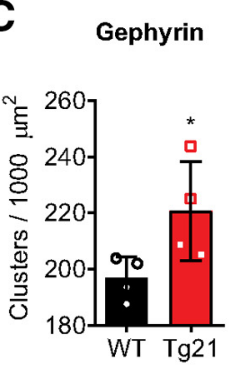

D

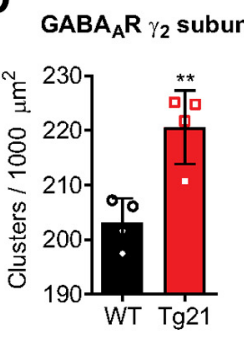

E

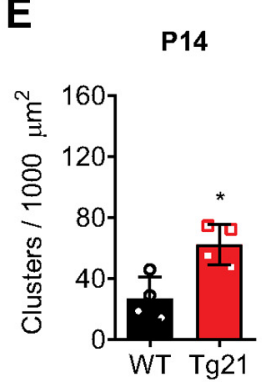

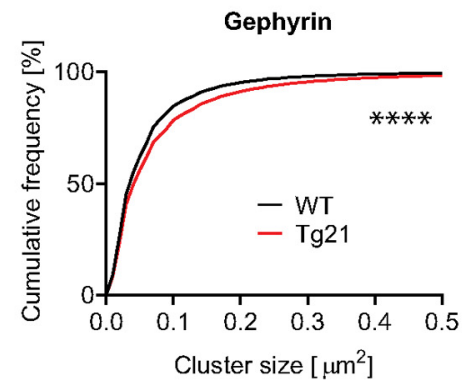

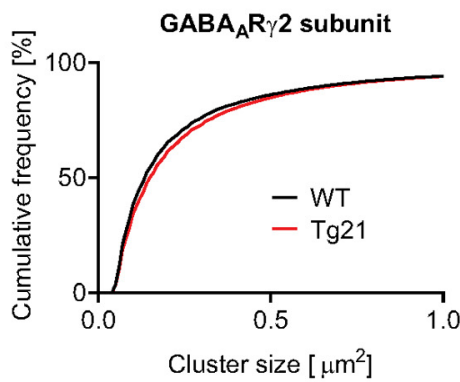

F

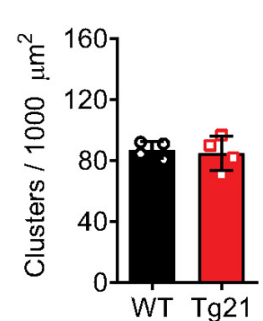

G

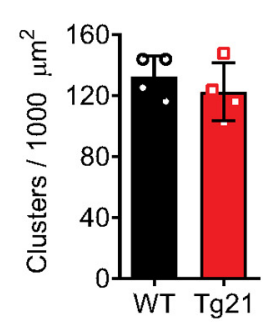

Figure 4. Increased $\mathrm{GABA}_{A} \mathrm{R}$ cluster density in CA1 pyramidal cells of Tg21 mice at $\mathrm{P} 14$. $\boldsymbol{A}$, Representative images of immunofluorescence staining against VGAT: vesicular GABA transporter (blue), gephyrin (green), and $\gamma 2-\mathrm{GABA}_{\mathrm{A}} \mathrm{R}$ subunit (red) in WT and Tg21 mice. B, Quantification of presynaptic (VGAT) terminals in WT and Tg21 mice showing increased terminal size (cumulative plot) in Tg21 mice. C, Quantification of postsynaptic clusters of gephyrin showing increased cluster number (bar graph) and size (cumulative plot). $\boldsymbol{D}$, Quantification of $\gamma_{2}-\mathrm{GABA}_{A} \mathrm{R}$ subunits in WT and Tg21 mice showing increased density (bar graph) in Tg21 mice. Density of postsynaptic (triple labeled) clusters in WT and Tg21 mice at P14 (E), P21(F), and P60 (G). Bar graphs show mean \pm SD, data points represent individual mice, $N=5$ animals per age and genotype, Student's $t$ test (B-J). Cumulative frequency plots show total number of quantified clusters in WT and Tg21 animals; ${ }^{\star} p<0.05,{ }^{\star \star} p<0.01,{ }^{* \star *} p<0.001$, ${ }^{* \star *} p<0.0001$. Scale bar: $10 \mu \mathrm{m}$.

animals had shorter interevent intervals (KS test, $p<0.01$; Fig. $5 B$ ) and hence higher frequency ( $t$ test, $p<0.001$ ); as well as larger amplitudes (KS test, $p<0.0001, t$ test, $p<0.01$; Fig. 5C) compared with WT. Additionally, the Tg21 kinetics were slower, with rise-time and decay-time constants being significantly longer than in WT [rise time: KS test, $p<0.0001, t$ test, $p<0.05$ (Fig. $5 D$ ); decay time:
KS test, $p=0.0002, t$ test $p<0.001$ (Fig. 5E)]. Therefore, overall GABAergic transmission onto pyramidal cells of Tg21 mice is enhanced. The larger amplitude of mIPSC correlates well with the increased size of $\mathrm{GABA}_{A} R$ clusters and suggests an increase in synaptic strength.

In slices taken from P19-P22 mice, no differences in interevent intervals/frequency (Fig. 5G) or event amplitude 
A

$\mathrm{P} 13-15$

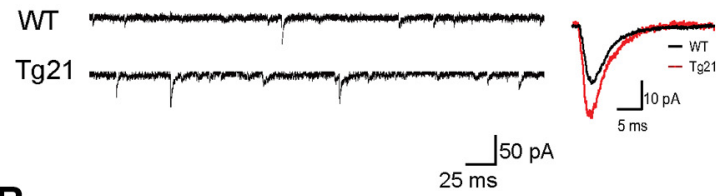

B

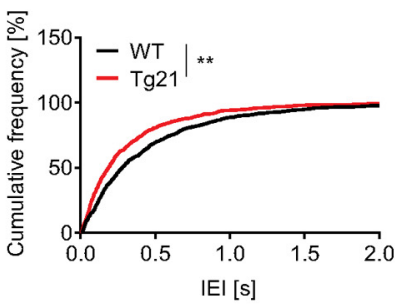

C

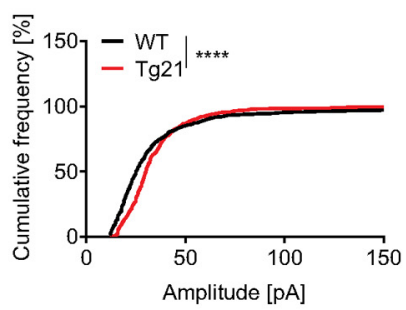

D

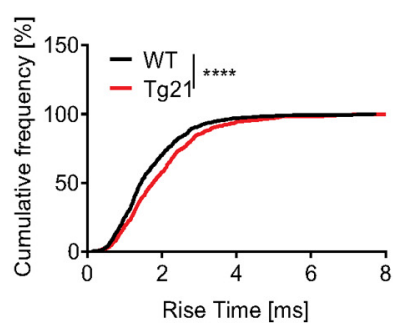

E
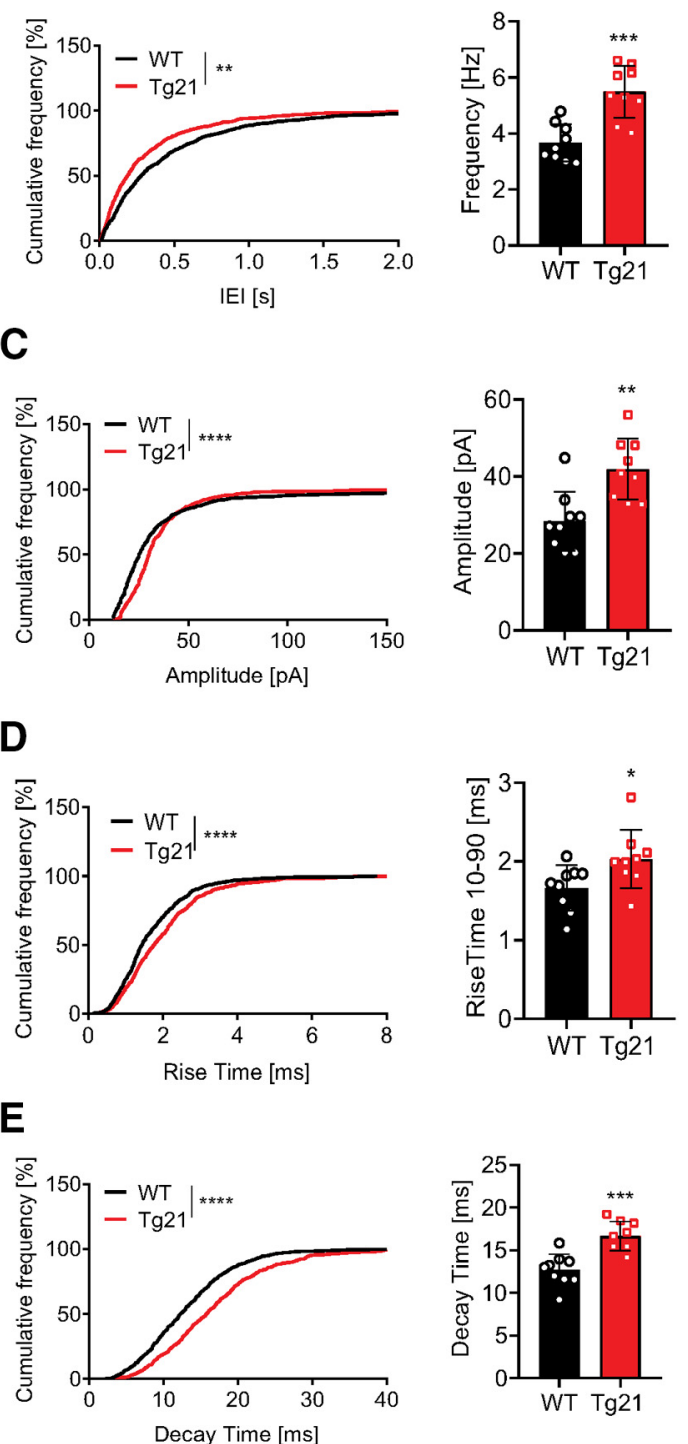

$\mathbf{F}$

P19-22

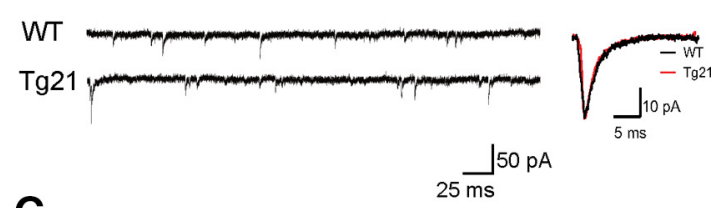

G
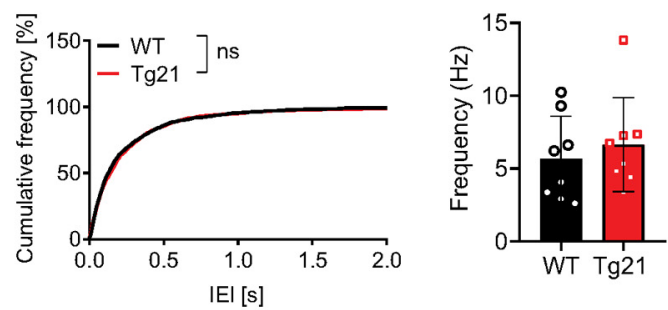

H
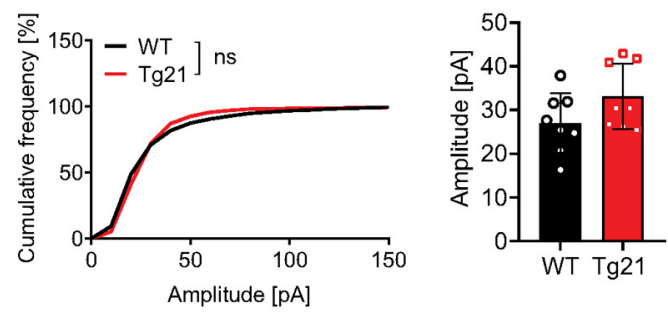

I
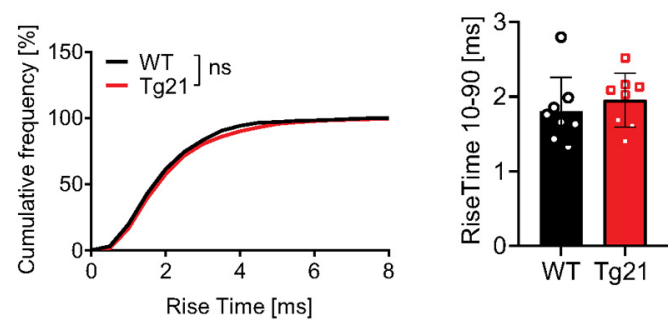

J

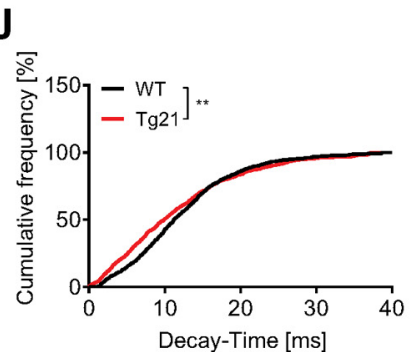

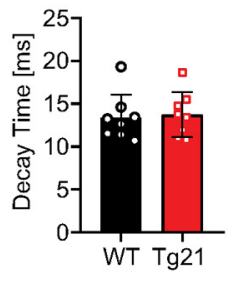

Figure 5. Enhancement of GABAergic synaptic transmission in CA1 area of Tg21 mice at P13-P15. $\boldsymbol{A}$, Representative raw and averaged mean traces of the mIPSCs in WT and Tg21 mice at P13-P15. B-E, Cumulative frequency distribution plots and data points graphs at P13-P15 of $(\boldsymbol{B})$ IEls and frequency, $(\boldsymbol{C})$ amplitude, $(\boldsymbol{D})$ rise-time constant, and $(\boldsymbol{E})$ decay-time constant of the mIPSCs from WT (black bars) and Tg21 (red bars). An increase in frequency, amplitude, rise time, and decay time is observed in Tg21mice at P13-P15. $\boldsymbol{F}$, Representative raw and averaged mean traces of the mIPSCs for WT and Tg21 mice at P19-P22. G-J, Cumulative frequency distribution plots at P19-P22 of (G) IEls and frequency, $(\boldsymbol{H})$ amplitude, $(\boldsymbol{I})$ risetime constant, and $(\boldsymbol{J})$ decay-time constant. No differences are observed in Tg21 mice at P19-P22. Graphs show mean \pm $\mathrm{SD}$, data points represent individual mice, $N=9$ animals per genotype (P13-P15) and $N=8$ animals (P19-P22), Student's $t$ test. Cumulative frequency plots show total number of events in WT and Tg21 animals, KS tests; ${ }^{*} p<0.05$, ${ }^{* *} p<0.01$, ${ }^{* \star *} p<0.001,{ }^{* * \star *} p<0.0001$. 
A

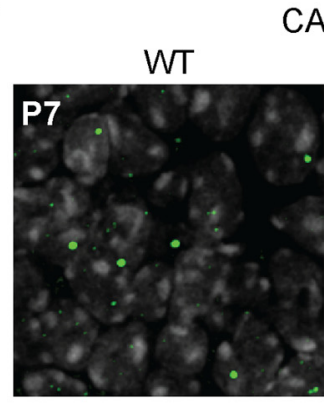

CA1 SP
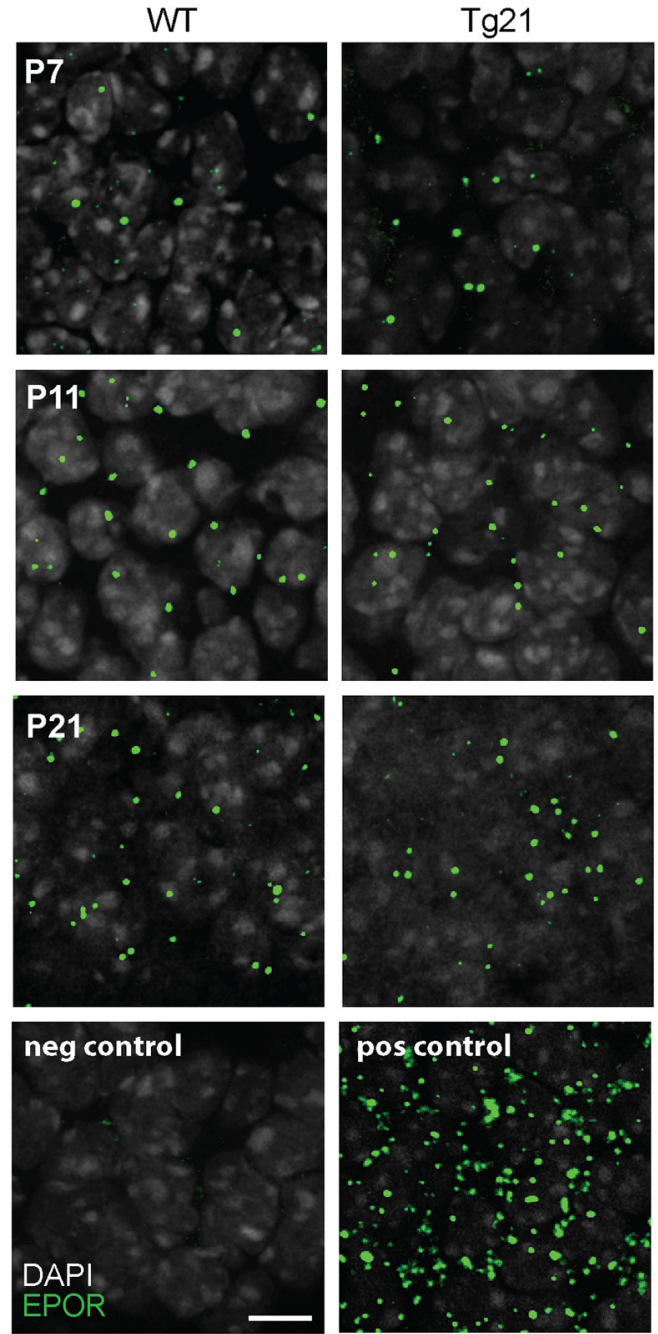

B

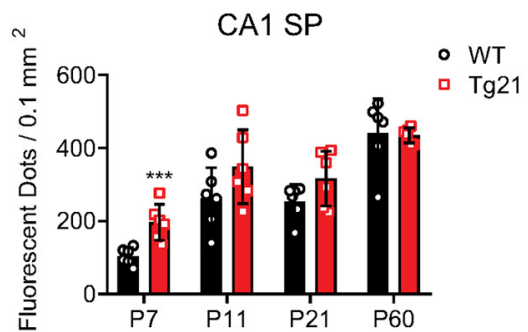

C
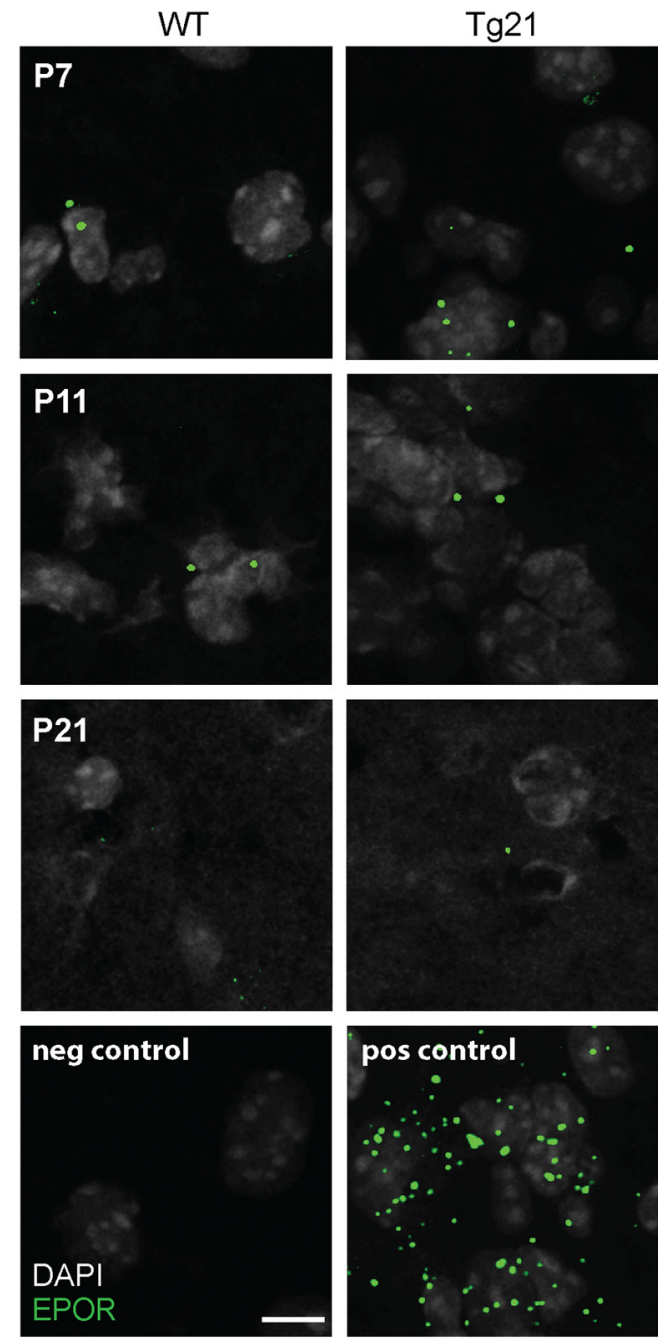

D

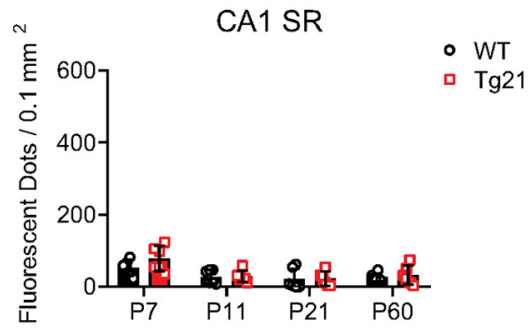

Figure 6. EPORs expression in the CA1 area is restricted to principal cells. Representative images of fISH for mRNA EPORs (green dots) colabeled with DAPI (gray) in WT and Tg21 mice at P7, P11, and P21 in (A) stratum pyramidale (SP) and (C) stratum radiatum (SR). Negative control (P7): fluorophore; positive control (P7): housekeeping gene. Scale bar: $10 \mu \mathrm{m}$. Quantification of EPOR mRNA dots in CA1 SP $(\boldsymbol{B})$ and CA1 SR $(\boldsymbol{D})$ at different postnatal ages, showing its selective presence in SP throughout postnatal development. More EPOR mRNA dots are quantified at P7 in Tg21 mice. Data are given as mean with individual values \pm SD, $N=6$ animals per genotype and age. Two-way ANOVA test; CA1 SP, ${ }^{* \star *} p<0.001$.

(Fig. $5 H$ ) of GABAergic mIPSCs were observed between Tg21 and WT mice. These results are in line with the morphologic analysis of GABAergic synaptic density at P21, in which no differences in synaptic clusters were observed between genotypes. At this age, mIPSCs kinetics in Tg21 mice became faster and equal to WT mice (Fig. 5/,ل).
EPORs are highly expressed in Tg21 mice CA1 pyramidal cells during early postnatal development

We next evaluated the cellular expression of EPORs in the hippocampus from WT and Tg21 mice. To this end, we performed fISH (RNA scope) of EPOR mRNA at postnatal ages P7, P11, P21, and P60. In both genotypes, 
A

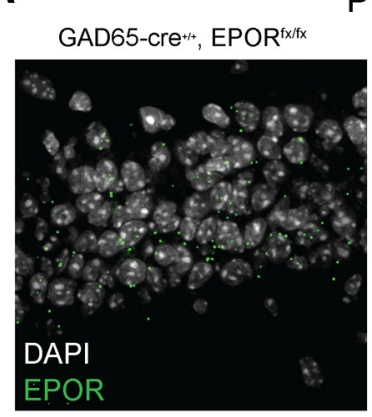

P11

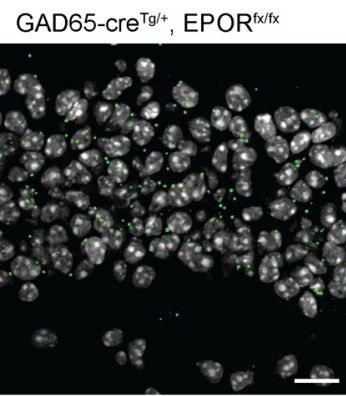

C

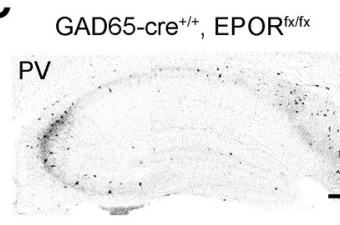

B

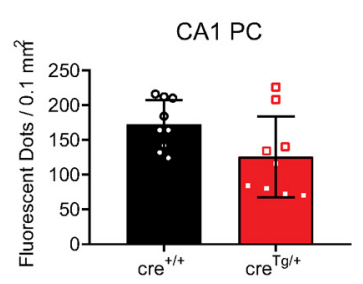

D

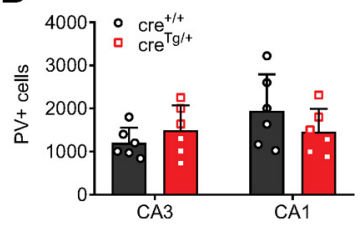

Figure 7. Constitutive deletion of EPORs from Gad65 cells has no impact on the GABAergic system. A, Representative images of $\mathrm{fISH}$ for EPORs in GAD65-cre ${ }^{+/+}, \mathrm{EPOR}^{\mathrm{fx} / \mathrm{fx}}$ mice and GAD65-cre ${ }^{\mathrm{g} /+}$, EPOR ${ }^{\mathrm{fx} / \mathrm{fx}}$ (GAD65: Glutamat decarboxylase isoform 65) mice at P11 in CA1 stratum pyramidale area. B, Quantification of EPOR mRNA dots in CA1 area, showing no effect of the targeted muta-

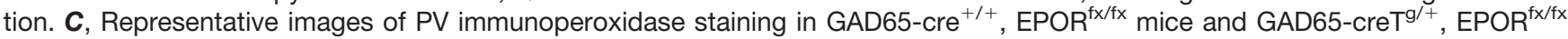
mice at $\mathrm{P} 11$ showing no change in PV immunostaining. $\boldsymbol{D}$, Unbiased quantification of $\mathrm{PV}^{+}$cell numbers in CA1 area shows no alteration in cell numbers on deletion of EPOR in interneurons. Data are given as mean $\pm \mathrm{SD}, N=3$ animals and 3 hippocampi per genotype for fISH and $N=6$ animals per genotype for PV stereology. Two-way ANOVA test. Scale bars: $10 \mu \mathrm{m}(\boldsymbol{A})$ and $200 \mu \mathrm{m}(\boldsymbol{C})$.

EPOR expression was found in pyramidal cells of the CA1 area (Fig. $6 A, B)$ and in a reduced number also in cells in the stratum radiatum (Fig. 6C,D). This finding strongly suggests a selective expression of EPOR mRNA in pyramidal cells throughout postnatal development. Quantification of EPOR mRNA probes in the stratum pyramidale of the CA1 area showed a significant age effect with increasing density of mRNA puncta until P60. Between P7 and P11, EPOR mRNA expression was mostly increased, reaching values like P21 and not significantly different from P60. At P7, Tg21 mice showed a 2-fold higher EPOR mRNA expression. No change in EPOR between genotypes was observed at any other age.

\section{Constitutive deletion of EPORs from Gad65 cells has no impact on the GABAergic system}

To further ensure that EPORs are mainly expressed in principal cells, fISH of EPOR mRNA along with immunolabeling of $\mathrm{PV}+$ cells was performed but no EPORs were found on PV+ cell in the hippocampus. Furthermore, the lack of EPOR expression on GABAergic cells was confirmed with the conditional deletion of EPOR $\left(\mathrm{EPOR}^{\mathrm{fx} / \mathrm{fx}}\right)$ in the GAD65-Cre ${ }^{\mathrm{Tg} /+}$, EPOR ${ }^{\mathrm{fx} / \mathrm{fx}}$ mouse line. In this line, EPOR expression was measured by fISH analysis at P11 (age when EPORs are highly incremented) in CA1 stratum pyramidale. Similar numbers of labeled puncta were detected in GAD65-Cre ${ }^{\mathrm{Tg} /+}, \mathrm{EPOR}^{\mathrm{fx} / \mathrm{fx}}$ and control GAD65-Cre $^{+/+}$, EPOR ${ }^{\mathrm{fx} / \mathrm{fx}}$ (unpaired $t$ test, $p=0.063$; Fig. $7 A, B)$. Also, the number of $\mathrm{PV}+$ cells in hippocampus were quantified at P11, showing no differences between control and gene-targeted mice (two-way ANOVA, $F_{(1,12)}=0.036, p=0.8523$; Fig. $\left.7 C, D\right)$, nor in neuropil formation, suggesting that the effects of EPO on the GABAergic system are most likely independent of EPOR expression in interneurons.

\section{Increased density of glutamatergic terminals on PV+ interneurons of Tg21 mice at P14}

Selective EPOR mRNA expression in principal cells of WT and Tg21 mice suggests that EPO might exert a trophic effect on pyramidal cells, which are known to strongly innervate neighboring $\mathrm{PV}+$ cells (feed-forward excitation). Therefore, we tested the hypothesis that glutamatergic input might be increased in PV+ interneurons in Tg21 mice. To this end, we used double immunofluorescence for PV and the two VGluT1 and VGluT2 in the CA1 and CA3 area at P14, the postnatal age where most changes in GABAergic transmission were observed (Fig. 8). Overall density of VGluT1/2-immunoreactive puncta revealed a significantly higher density of VGluT1/ 2-immunoreactive terminals contacting $\mathrm{PV}+$ interneurons in CA1 and CA3 (unpaired $t$ test, $p=0.0011$; Fig. $8 A, B$ ), with no change in the size of these terminals (Fig. $8 C, D$ ), suggesting that increased synaptic excitatory inputs onto $\mathrm{PV}$ cells might drive the accelerated maturation of $\mathrm{PV}+$ cells observed in Tg21 mice.

Thus, in summary, we conclude that the effect of EPO on GABAergic postnatal maturation results from pyramidal regulation of interneuron network formation and survival.

\section{Discussion}

The present study shows that constitutive neuronal overexpression of EPO stimulates maturation of the 
A
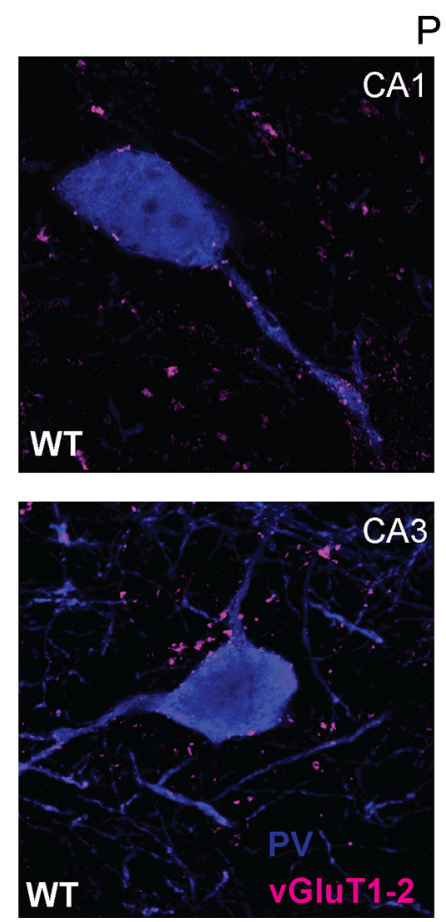

P14
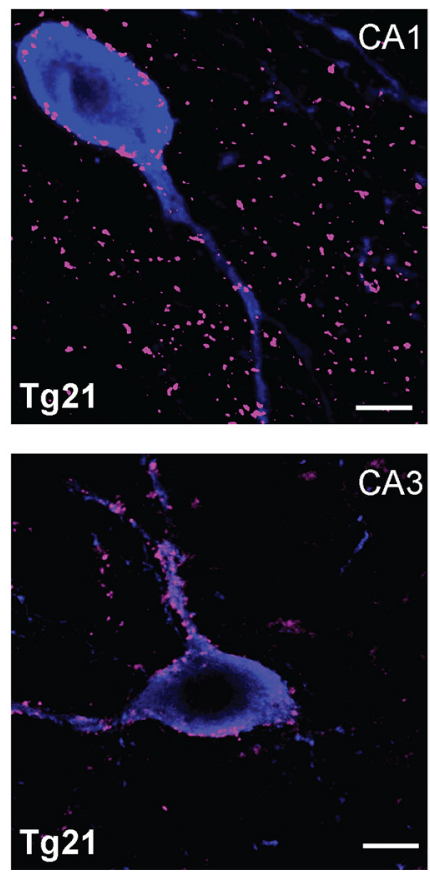

B

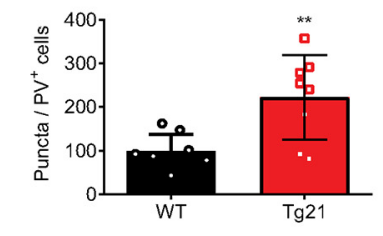

C

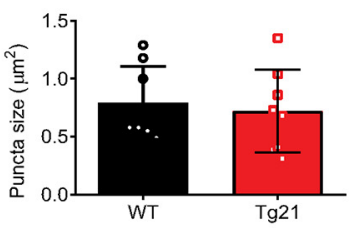

D

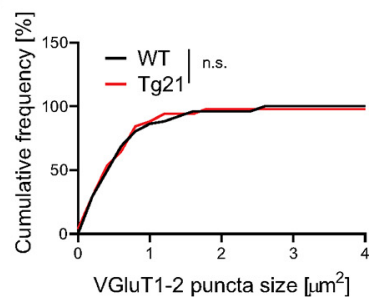

Figure 8. Increased density of glutamatergic terminals on PV+ interneurons of Tg21 mice at P14. $\boldsymbol{A}$, Representative images of double immunofluorescence staining for VGluT1-2 (magenta) and PV (blue) in hippocampus of WT and Tg21 mice. B, Quantification of VGluT1\&2+ puncta in PV + cells, showing higher numbers in Tg21 mice. $\boldsymbol{C}, \boldsymbol{D}$, No change in puncta size between genotypes was observed. Bar graphs are given as mean $\pm \mathrm{SD}, N=4$ animals per genotype and 2 hippocampi per animal. 10 to $15 \mathrm{PV}+\mathrm{cells}$ were quantified per hippocampi and area. Student's t test, ${ }^{\star *} p, 0.01$, KS tests n.s. Scale bar: $10 \mathrm{~mm}$.

GABAergic system in the mouse hippocampus. EPO overexpression affected numerous aspects of GABAergic maturation during the second and third postnatal window, namely elevated expression of GABAergic cells and markers of GABAergic neurons (mainly PV, SST, and NPY), increased GABAergic synapse density and function in pyramidal cells, faster maturation of PV + /WFA + cells, and increased innervation of PV + interneurons by glutamatergic terminals. All these changes suggest enhanced GABAergic function during a critical period for the proper formation of brain circuits. EPO overexpression in neurons caused a reduction in apoptosis in the CA1 and CA3 hippocampus during the first postnatal week, when EPORs were upregulated in principal cells of the Tg21 mice. Therefore, survival of interneurons during this postnatal window is essential for postnatal development and circuit formation. The lack of EPORs on interneurons, confirmed by the lack of a phenotype observed in the Gad65-cre, EPOR ${ }^{\mathrm{f} / \mathrm{fx}}$ mice, additionally suggests pyramidal cells to regulate interneuron survival (Wong et al., 2018). Our results support the notion that EPO can indirectly stimulate the development of GABAergic transmission, which in turn is a key driver of neural circuit formation. Therefore, EPO could be highly beneficial in pathologic conditions that affect GABAergic neurons and might protect the brain against an imbalance of excitatory/inhibitory transmission.

We showed an increase in GABAergic neurons (mainly PV, SST, and NPY) during postnatal hippocampal development caused by a decrease in apoptosis during the first postnatal week. The reduction in apoptosis was mainly observed in the stratum pyramidale of CA3 and CA1 areas and in the CA1 stratum oriens, which compress oriens-lacunosum moleculare interneurons (O-LM) that express SST and NPY. The restricted location of cell somata in the CA1 stratum oriens dictates that the source of excitatory inputs is mainly from pyramidal cells, therefore survival and enhancement of glutamatergic inputs is also expected to occur in SST and NPY cells. At P14 PVexpressing cells are increased mainly in the CA3 area, whereas SST-expressing cells were increased in the CA1 area. Most cells in the CA1 stratum oriens showed reduced apoptosis at P7, therefore the increase in SST number could be linked to survival.

Whether EPO-mediated enhancement of interneurons is also linked to EPO signaling on inhibitory neurons during embryonic origin is unlikely, since deletion of EPORs on Gad65-cre cells had no effect on normal GABAergic development, and EPORs start to express postnatally in the hippocampus. In the neocortex, EPO and EPORs are expressed embryonically in the neurogenic ventricular zone and EPO signaling is required for radial migration and laminar positioning of upper-layer excitatory neurons (Constanthin et al., 2020). In contrast to the cortex, we show in this study that EPO signals in the hippocampus postnatally. We show that EPORs are expressed on CA1 pyramidal neurons and the expression increases 
postnatally to reach a zenith at early adulthood (P60). It is important to emphasize that in we have confirmed activation of the ERK and AKT pathway across postnatal development in the hippocampus of Tg21 mice and in a model of stroke (Kilic et al., 2005). Therefore, EPO-mediated activation of PI3K-AKT and Erk1/2 extends from neuroprotection to influencing neuronal differentiation postnatally. Activation of AKT signaling is known to mediate phosphorylation of the $G A B A_{A} R \gamma_{2}$ subunit, resulting in increased $G_{A B A_{A}} R$ trafficking to the postsynaptic membrane and facilitation of GABAergic inhibitory transmission (Wang et al., 2003). Furthermore, clustering of gephyrin at postsynaptic sites is modulated by various posttranslational modifications, notably by PI3K/Akt (Tyagarajan and Fritschy, 2014). Modulation of gephyrin phosphorylation has been shown to influence the density of GABAergic synapses on dendrites in vitro and in vivo (Tyagarajan et al., 2011). In our model, we observed an increase in $\mathrm{GABA}_{\mathrm{A}} \mathrm{R} \gamma_{2}$ postsynaptic clusters and an increase in $\mathrm{GABA}_{\mathrm{A}} \mathrm{R} \gamma_{2}$ and gephyrin cluster size, along with enhanced IPSCs during the postnatal development. Since EPORs are highly expressed in CA1 pyramidal cells starting from $\mathrm{P} 11$, we propose that EPO signaling onto pyramidal cells activates the PI3K/Akt pathway, leading to an increase in $\mathrm{GABA}_{\mathrm{A}} \mathrm{R}$ trafficking to the membrane and resulting in increased synaptic GABAergic function in CA1 pyramidal cells. ERK1/2 phosphorylation is also implicated in the differentiation of neurons (Li et al., 2006) and synaptic hippocampal plasticity in the CA1 area (Kanterewicz et al., 2000). However, no evidence for in vivo ERK1/2 regulation of $\mathrm{GABA}_{A}$ Rs has been reported so far. Furthermore, EPO causes an increase in presynaptic VGAT size. Therefore, the effect of EPO overexpression on the GABAergic synapses is likely presynaptic and postsynaptic, through the bidirectional signaling of the neuroligin-neurexin complex (Shen and Scheiffele, 2010). Additionally, it is possible that EPO acts via activation of the TrkB/BDNF pathway, causing an increase in presynaptic VGAT expression (Wang and Xia, 2015).

We show, by the evaluation of PNN formation, that EPO overexpression does not change the onset nor the number of PV + cells surrounded by PNNs but enhances PV and PNN staining intensity. This suggests that EPO accelerates interneuron maturation. The increase in maturation is in line with the observed increase of excitatory VGluT1 and VGluT2 inputs to PV+ cells and the strengthening of inhibitory synapses to pyramidal neurons in the CA1 area, as seen at P13-P15 by the increase in mIPSC frequency and amplitude. Interestingly, in Tg21 mice, PV+/WFA+ cells exhibit significantly larger soma at P11, leading to the question of whether PV + cell size is also related to increased synaptic plasticity. PV expression is linked to synaptic density ratios. Specifically; high PV expression means more differentiation and a higher excitatory/inhibitory ratio (Donato et al., 2013). Additionally, PNNs preferentially form around more mature $\mathrm{PV}+$ cells with a higher staining intensity (Donato et al., 2013). No changes in PV staining intensity and soma size were seen at other postnatal ages, and at P26 the number of $\mathrm{PV}+$ cells surrounded by PNNs was equal in both genotypes. Therefore, EPO may stimulate the maturation of late PV-basket cells, which exhibit plasticity when the critical period of plasticity is induced (Donato et al., 2015). Indeed, an increase in PV+/WFA- cells, in which plasticity remains high, was quantified in Tg21 mice at P11.

$\mathrm{PV}+$ basket cells provide powerful perisomatic feedforward and feedback inhibitory inputs onto CA1 pyramidal cells (Klausberger and Somogyi, 2008). The maturation stage of PV-basket cells has been implicated in different forms of learning since each interneuron type selectively gates distinct information flow to pyramidal cells. Accordingly, changes at different times within the period of plasticity might differ in network formation and the response to specific learning requirements. The capability of EPO to increase, on the one hand, the number of immature PV + cells and to stimulate, on the other hand, the maturation of PV-basket cells makes this paradigm relevant for therapeutic applications in the treatment of developmental disabilities.

One of the central interests in neurodevelopmental therapy is to identify pharmacological interventions that stimulate neural synaptic plasticity. Moreover, the hippocampus is an area of high clinical interest, since the integrity of synaptic function is implicated in several disease states caused by perinatal injury (Travaglia et al., 2016; Alberini and Travaglia, 2017), and early interventions are required. Many studies reported EPO as an efficient neuroprotective agent in models of experimental stroke (Wiessner et al., 2001), cerebral hypoxic-ischemia, PBI, and neuroinflammation (Sirén et al., 2009). In the hippocampus, it inhibits apoptosis associated with glutamate toxicity, and promotes survival and neurogenesis (Doggrell, 2004; Mennini et al., 2006; Hassouna et al., 2016; Zhang et al., 2018). Several clinical trials in neonatology using a high dose of recombinant human EPO given in the first days of life (from 500 to $5000 \mathrm{IU} / \mathrm{kg}$, i.p., to pass the blood brain barrier) have shown that EPO cannot only reduce acute injury but represents a promising tool for long-lasting prevention of trauma-induced developmental delay, as well as cognitive and neurobehavioral dysfunction (Sirén et al., 2009; Natalucci et al., 2016). Accumulating evidence from animal studies suggests EPO is an enhancer of hippocampal synaptic plasticity and cognition in the mature hippocampus (Adamcio et al., 2008; Dias et al., 2018), as well as in patients with psychiatric diseases (Ehrenreich et al., 2007a,b, 2008; Miskowiak et al., 2010, 2015, 2016). However, whether EPO can stimulate neurodevelopment and specifically the maturation of the inhibitory synaptic transmission has remained elusive. With this work, we provide an ideal model to amplify EPO's physiological effects during postnatal brain development without altering blood cell production. We could show EPO's potential in stimulating postnatal maturation of neurons in the hippocampus, and additionally, we identified the targets through which EPO signals. The impact of EPO on GABAergic interneurons is a network effect in which increased glutamatergic inputs to PV+ cells and increase GABAergic inputs to pyramidal cells is observed early in postnatal development. 
Our work supports the use of EPO to stimulate neurodevelopment. Since EPO is controlled via the HIF-2/prolyl hydroxylase 2 (PHD2) pathway (Takeda et al., 2008; Gassmann and Muckenthaler, 2015), inhibitors of PHD2 to stabilize the $\alpha$-subunit of HIF-2 and subsequently increase transcription of the EPO gene are being commercialized (Soni, 2014). These components are small and can cross the blood brain barrier, so it is to be expected that they will inhibit PHD2 activity in neurons, thus being a potential therapy to increase neuronal EPO production and stimulate neuronal maturation.

In summary, our data provide evidence that EPO accelerates the maturation of the GABAergic system in the neonatal (P7-P14) hippocampus, without causing network imbalance. The results support the use of EPO as a therapeutic agent to stimulate normal brain development after PBI.

\section{References}

Adamcio B, Sargin D, Stradomska A, Medrihan L, Gertler C, Theis F, Zhang $M$, Müller $M$, Hassouna I, Hannke K, Sperling $S$, Radyushkin K, El-Kordi A, Schulze L, Ronnenberg A, Wolf F, Brose N, Rhee JS, Zhang W, Ehrenreich H (2008) Erythropoietin enhances hippocampal long-term potentiation and memory. BMC Biol 6:37.

Alberini CM, Travaglia A (2017) Infantile amnesia: a critical period of learning to learn and remember. J Neurosci 37:5783-5795.

Almaguer-Melian W, Mercerón-Martínez D, Pavón-Fuentes $\mathrm{N}$, Alberti-Amador E, Leon-Martinez R, Ledón N, Delgado Ocaña S, Bergado Rosado JA (2015) Erythropoietin promotes neural plasticity and spatial memory recovery in fimbria-fornix-lesioned rats. Neurorehabil Neural Repair 29:979-988.

Begum MR, Sng JCG (2017) Molecular mechanisms of experiencedependent maturation in cortical GABAergic inhibition. J Neurochem 142:649-661.

Ben-Ari Y, Gaiarsa JL, Tyzio R, Khazipov R (2007) GABA: a pioneer transmitter that excites immature neurons and generates primitive oscillations. Physiol Rev 87:1215-1284.

Castaneda-Arellano R, Beas-Zarate C, Feria-Velasco Al, BitarAlatorre EW, Rivera-Cervantes MC (2014) From neurogenesis to neuroprotection in the epilepsy: signalling by erythropoietin. Front Biosci (Landmark Ed) 19:1445-1455.

Constanthin PE, Contestabile A, Petrenko V, Quairiaux C, Salmon P, Hüppi PS, Kiss JZ (2020) Endogenous erythropoietin signaling regulates migration and laminar positioning of upper-layer neurons in the developing neocortex. Development 147:dev190249.

Cunha-Rodrigues MC, Balduci CTDN, Tenório F, Barradas PC (2018) GABA function may be related to the impairment of learning and memory caused by systemic prenatal hypoxia-ischemia. Neurobiol Learn Mem 149:20-27.

Dias RB, Rodrigues TM, Rombo DM, Ribeiro FF, Rodrigues J, McGarvey J, Orcinha C, Henley JM, Sebastião AM (2018) Erythropoietin induces homeostatic plasticity at hippocampal synapses. Cereb Cortex 28:2795-2809.

Digicaylioglu M, Bichet S, Marti HH, Wenger RH, Rivas LA, Bauer C, Gassmann M (1995) Localization of specific erythropoietin binding sites in defined areas of the mouse brain. Proc Natl Acad Sci USA 92:3717-3720.

Doggrell SA (2004) A neuroprotective derivative of erythropoietin that is not erythropoietic. Expert Opin Investig Drugs 13:1517-1519.

Donato F, Rompani SB, Caroni P (2013) Parvalbumin-expressing basket-cell network plasticity induced by experience regulates adult learning. Nature 504:272-276.

Donato F, Chowdhury A, Lahr M, Caroni P (2015) Early- and lateborn parvalbumin basket cell subpopulations exhibiting distinct regulation and roles in learning. Neuron 85:770-786.
Dzyubenko E, Juckel G, Faissner A (2017) The antipsychotic drugs olanzapine and haloperidol modify network connectivity and spontaneous activity of neural networks in vitro. Sci Rep 7:11609.

Ehrenreich H, Fischer B, Norra C, Schellenberger F, Stender N, Stiefel M, Sirén AL, Paulus W, Nave KA, Gold R, Bartels C (2007a) Exploring recombinant human erythropoietin in chronic progressive multiple sclerosis. Brain 130:2577-2588.

Ehrenreich H, Hinze-Selch D, Stawicki S, Aust C, Knolle-Veentjer S, Wilms S, Heinz G, Erdag S, Jahn H, Degner D, Ritzen M, Mohr A, Wagner M, Schneider U, Bohn M, Huber M, Czernik A, Pollmächer T, Maier W, Sirén AL, et al. (2007b) Improvement of cognitive functions in chronic schizophrenic patients by recombinant human erythropoietin. Mol Psychiatry 12:206-220.

Ehrenreich H, Bartels C, Sargin D, Stawicki S, Krampe H (2008) Recombinant human erythropoietin in the treatment of human brain disease: focus on cognition. J Ren Nutr 18:146-153.

Farrell F, Lee A (2004) The erythropoietin receptor and its expression in tumor cells and other tissues. Oncologist 9 [Suppl 5]:18-30.

Faul F, Erdfelder E, Lang AG, Buchner A (2007) G*Power 3: a flexible statistical power analysis program for the social, behavioral, and biomedical sciences. Behav Res Methods 39:175-191.

Fowke TM, Galinsky R, Davidson JO, Wassink G, Karunasinghe RN, Prasad JD, Bennet L, Gunn AJ, Dean JM (2018) Loss of interneurons and disruption of perineuronal nets in the cerebral cortex following hypoxia-ischaemia in near-term fetal sheep. Sci Rep 8:17686.

Fritschy JM, Mohler H (1995) GABAA-receptor heterogeneity in the adult rat brain: differential regional and cellular distribution of seven major subunits. J Comp Neurol 359:154-194.

Früh $S$, Romanos J, Panzanelli $P$, Bürgisser $D$, Tyagarajan SK, Campbell KP, Santello M, Fritschy JM (2016) Neuronal dystroglycan is necessary for formation and maintenance of functional CCK-positive basket cell terminals on pyramidal cells. J Neurosci 36:10296-10313.

Gassmann M, Muckenthaler MU (2015) Adaptation of iron requirement to hypoxic conditions at high altitude. J Appl Physiol (1985) 119:1432-1440.

Ghezzi P, Brines M (2004) Erythropoietin as an antiapoptotic, tissueprotective cytokine. Cell Death Differ 11 [Suppl 1]:S37-S44.

Hassouna I, Ott C, Wüstefeld L, Offen N, Neher RA, Mitkovski M, Winkler D, Sperling S, Fries L, Goebbels S, Vreja IC, Hagemeyer N, Dittrich M, Rossetti MF, Kröhnert K, Hannke K, Boretius S, Zeug A, Höschen C, Dandekar T, et al. (2016) Revisiting adult neurogenesis and the role of erythropoietin for neuronal and oligodendroglial differentiation in the hippocampus. Mol Psychiatry 21:1752-1767.

Hensch TK (2005) Critical period mechanisms in developing visual cortex. Curr Top Dev Biol 69:215-237.

Hensch TK, Bilimoria PM (2012) Re-opening windows: manipulating critical periods for brain development. Cerebrum 2012:11.

Holló K, Ducza L, Hegyi Z, Dócs K, Hegedüs K, Bakk E, Papp I, Kis G, Mészár Z, Bardóczi Z, Antal M (2017) Interleukin-1 receptor type 1 is overexpressed in neurons but not in glial cells within the rat superficial spinal dorsal horn in complete Freund adjuvant-induced inflammatory pain. J Neuroinflammation 14:125.

Huang ZJ, Kirkwood A, Pizzorusso T, Porciatti V, Morales B, Bear MF, Maffei L, Tonegawa S (1999) BDNF regulates the maturation of inhibition and the critical period of plasticity in mouse visual cortex. Cell 98:739-755.

Jantzie LL, Miller RH, Robinson S (2013) Erythropoietin signaling promotes oligodendrocyte development following prenatal systemic hypoxic-ischemic brain injury. Pediatr Res 74:658-667.

Jantzie LL, Getsy PM, Firl DJ, Wilson CG, Miller RH, Robinson S (2014) Erythropoietin attenuates loss of potassium chloride cotransporters following prenatal brain injury. Mol Cell Neurosci 61:152-162.

Juul SE, Pet GC (2015) Erythropoietin and neonatal neuroprotection. Clin Perinatol 42:469-481.

Juul SE, Mayock DE, Comstock BA, Heagerty PJ (2015) Neuroprotective potential of erythropoietin in neonates; design of a randomized trial. Matern Health Neonatol Perinatol 1:27. 
Kamal A, Al Shaibani T, Ramakers G (2011) Erythropoietin decreases the excitatory neurotransmitter release probability and enhances synaptic plasticity in mice hippocampal slices. Brain Res 1410:3337.

Kanterewicz BI, Urban NN, McMahon DBT, Norman ED, Giffen LJ, Favata MF, Scherle PA, Trzăskos JM, Barrionuevo G, Klann E (2000) The extracellular signal-regulated kinase cascade is required for NMDA receptor-independent LTP in area CA1 but not area CA3 of the hippocampus. J Neurosci 20:3057-3066.

Kilic E, Kilic U, Hermann DM (2005) TAT-GDNF in neurodegeneration and ischemic stroke. CNS Drug Rev 11:369-378.

Klausberger T, Somogyi P (2008) Neuronal diversity and temporal dynamics: the unity of hippocampal circuit operations. Science 321:53-57.

Komitova M, Xenos D, Salmaso N, Tran KM, Brand T, Schwartz ML, Ment L, Vaccarino FM (2013) Hypoxia-induced developmental delays of inhibitory interneurons are reversed by environmental enrichment in the postnatal mouse forebrain. J Neurosci 33:1337513387.

Lacaille H, Vacher C-M, Bakalar D, O’Reilly JJ, Salzbank J, Penn AA (2019) Impaired interneuron development in a novel model of neonatal brain injury. eNeuro 6:ENEURO.0300-18.2019.

Li Z, Theus MH, Wei L (2006) Role of ERK 1/2 signaling in neuronal differentiation of cultured embryonic stem cells. Dev Growth Differ 48:513-523.

Lombardero M, Kovacs K, Scheithauer BW (2011) Erythropoietin: a hormone with multiple functions. Pathobiology 78:41-53.

Mackay JP, Bompolaki M, DeJoseph MR, Michaelson SD, Urban JH, Colmers WF (2019) NPY2 receptors reduce tonic action potentialindependent GABAB currents in the basolateral amygdala. J Neurosci 39:4909-4930.

Marin O (2012) Interneuron dysfunction in psychiatric disorders. Nat Rev Neurosci 13:107-120.

Marti HH, Wenger RH, Rivas LA, Straumann U, Digicaylioglu M, Henn V, Yonekawa Y, Bauer C, Gassmann M (1996) Erythropoietin gene expression in human, monkey and murine brain. Eur $\mathrm{J}$ Neurosci 8:666-676.

Mennini T, De Paola M, Bigini P, Mastrotto C, Fumagalli E, Barbera S, Mengozzi M, Viviani B, Corsini E, Marinovich M, Torup L, Van Beek J, Leist M, Brines M, Cerami A, Ghezzi P (2006) Nonhematopoietic erythropoietin derivatives prevent motoneuron degeneration in vitro and in vivo. Mol Med 12:153-160.

Miskowiak KW, Favaron E, Hafizi S, Inkster B, Goodwin GM, Cowen PJ, Harmer CJ (2010) Erythropoietin modulates neural and cognitive processing of emotional information in biomarker models of antidepressant drug action in depressed patients. Psychopharmacology (Berl) 210:419-428.

Miskowiak KW, Vinberg M, Macoveanu J, Ehrenreich H, Køster N, Inkster B, Paulson OB, Kessing LV, Skimminge A, Siebner HR (2015) Effects of erythropoietin on hippocampal volume and memory in mood disorders. Biol Psychiatry 78:270-277.

Miskowiak KW, Macoveanu J, Vinberg M, Assentoft E, Randers L, Harmer CJ, Ehrenreich H, Paulson OB, Knudsen GM, Siebner HR, Kessing LV (2016) Effects of erythropoietin on memory-relevant neurocircuitry activity and recall in mood disorders. Acta Psychiatr Scand 134:249-259.

Mullen RJ, Buck CR, Smith AM (1992) NeuN, a neuronal specific nuclear protein in vertebrates. Development 116:201-211.

Natalucci G, Latal B, Koller B, Rüegger C, Sick B, Held L, Bucher HU, Fauchère JC, Swiss EPONTG; Swiss EPO Neuroprotection Trial Group (2016) Effect of early prophylactic high-dose recombinant human erythropoietin in very preterm infants on neurodevelopmental outcome at 2 years: a randomized clinical trial. JAMA 315:2079-2085.

Noguchi CT, Asavaritikrai P, Teng R, Jia Y (2007) Role of erythropoietin in the brain. Crit Rev Oncol Hematol 64:159-171.

Pan-Vazquez A, Wefelmeyer W, Gonzalez Sabater V, Neves G, Burrone J (2020) Activity-dependent plasticity of axo-axonic synapses at the axon initial segment. Neuron 106:265-276.e6.
Paxinos GF (2007) The mouse brain in stereotaxic coordinates. San Diego: Academic Press.

Priya R, Paredes MF, Karayannis T, Yusuf N, Liu X, Jaglin X, Graef I, Alvarez-Buylla A, Fishell G (2018) Activity regulates cell death within cortical interneurons through a calcineurin-dependent mechanism. Cell Rep 22:1695-1709.

Rangarajan V, Juul SE (2014) Erythropoietin: emerging role of erythropoietin in neonatal neuroprotection. Pediatr Neurol 51:481-488.

Robinson S, Li Q, Dechant A, Cohen ML (2006) Neonatal loss of gamma-aminobutyric acid pathway expression after human perinatal brain injury. J Neurosurg 104:396-408.

Roseti C, Cifelli P, Ruffolo G, Barbieri E, Guescini M, Esposito V, Gennaro GD, Limatola C, Giovannelli A, Aronica E, Palma E (2020) Erythropoietin increases GABAA currents in human cortex from TLE patients. Neuroscience 439:153-162.

Ruschitzka FT, Wenger RH, Stallmach T, Quaschning T, de Wit C, Wagner K, Labugger R, Kelm M, Noll G, Rülicke T, Shaw S, Lindberg RL, Rodenwaldt B, Lutz H, Bauer C, Lüscher TF, Gassmann M (2000) Nitric oxide prevents cardiovascular disease and determines survival in polyglobulic mice overexpressing erythropoietin. Proc Natl Acad Sci USA 97:11609-11613.

Sargin D, El-Kordi A, Agarwal A, Müller M, Wojcik SM, Hassouna I, Sperling S, Nave KA, Ehrenreich H (2011) Expression of constitutively active erythropoietin receptor in pyramidal neurons of cortex and hippocampus boosts higher cognitive functions in mice. BMC Biol 9:27.

Schneider Gasser EM, Straub CJ, Panzanelli P, Weinmann O, Sassoè-Pognetto M, Fritschy JM (2006) Immunofluorescence in brain sections: simultaneous detection of presynaptic and postsynaptic proteins in identified neurons. Nat Protoc 1:1887-1897.

Shen K, Scheiffele P (2010) Genetics and cell biology of building specific synaptic connectivity. Annu Rev Neurosci 33:473-507.

Sirén AL, Fasshauer T, Bartels C, Ehrenreich H (2009) Therapeutic potential of erythropoietin and its structural or functional variants in the nervous system. Neurotherapeutics 6:108-127.

Slaker ML, Harkness JH, Sorg BA (2016) A standardized and automated method of perineuronal net analysis using. IBRO Rep 1:5460.

Slomianka L, West MJ (2005) Estimators of the precision of stereological estimates: an example based on the CA1 pyramidal cell layer of rats. Neuroscience 136:757-767.

Solbach S, Celio MR (1991) Ontogeny of the calcium binding protein parvalbumin in the rat nervous system. Anat Embryol (Berl) 184:103-124.

Soni H (2014) Prolyl hydroxylase domain-2 (PHD2) inhibition may be a better therapeutic strategy in renal anemia. Med Hypotheses 82:547-550.

Southwell DG, Paredes MF, Galvao RP, Jones DL, Froemke RC, Sebe JY, Alfaro-Cervello C, Tang Y, Garcia-Verdugo JM, Rubenstein JL, Baraban SC, Alvarez-Buylla A (2012) Intrinsically determined cell death of developing cortical interneurons. Nature 491:109-113.

Takeda K, Aguila HL, Parikh NS, Li X, Lamothe K, Duan LJ, Takeda H, Lee FS, Fong GH (2008) Regulation of adult erythropoiesis by prolyl hydroxylase domain proteins. Blood 111:3229-3235.

Teoh JJ, Iwano T, Kunii M, Atik N, Avriyanti E, Yoshimura SI, Moriwaki K, Harada A (2017) BIG1 is required for the survival of deep layer neurons, neuronal polarity, and the formation of axonal tracts between the thalamus and neocortex in developing brain. PLoS One 12:e0175888.

Travaglia A, Bisaz R, Sweet ES, Blitzer RD, Alberini CM (2016) Infantile amnesia reflects a developmental critical period for hippocampal learning. Nat Neurosci 19:1225-1233.

Tyagarajan SK, Fritschy JM (2014) Gephyrin: a master regulator of neuronal function? Nat Rev Neurosci 15:141-156.

Tyagarajan SK, Ghosh H, Yévenes GE, Nikonenko I, Ebeling C, Schwerdel C, Sidler C, Zeilhofer HU, Gerrits B, Muller D, Fritschy JM (2011) Regulation of GABAergic synapse formation and plasticity by GSK3beta-dependent phosphorylation of gephyrin. Proc Natl Acad Sci USA 108:379-384. 
Tyzio R, Holmes GL, Ben-Ari Y, Khazipov R (2007) Timing of the developmental switch in $\mathrm{GABA}(\mathrm{A})$ mediated signaling from excitation to inhibition in CA3 rat hippocampus using gramicidin perforated patch and extracellular recordings. Epilepsia 48 [Suppl 5]:96-105.

Vaghi V, Pennucci R, Talpo F, Corbetta S, Montinaro V, Barone C, Croci L, Spaiardi P, Consalez GG, Biella G, de Curtis I (2014) Rac1 and rac3 GTPases control synergistically the development of cortical and hippocampal GABAergic interneurons. Cereb Cortex 24:1247-1258.

Wang P, Xia F (2015) EPO protects Muller cell under high glucose state through BDNF/TrkB pathway. Int J Clin Exp Pathol 8:80838090.

Wang Q, Liu L, Pei L, Ju W, Ahmadian G, Lu J, Wang Y, Liu F, Wang YT (2003) Control of synaptic strength, a novel function of Akt. Neuron 38:915-928.

Wei H, Ma Y, Ding C, Jin G, Liu J, Chang Q, Hu F, Yu L (2016) Reduced glutamate release in adult BTBR mouse model of autism spectrum disorder. Neurochem Res 41:3129-3137.

Wiessner C, Allegrini PR, Ekatodramis D, Jewell UR, Stallmach T, Gassmann M (2001) Increased cerebral infarct volumes in polyglobulic mice overexpressing erythropoietin. J Cereb Blood Flow Metab 21:857-864.

Wojtowicz T, Mozrzymas JW (2008) Erythropoietin affects GABAergic transmission in hippocampal neurons in vitro. Cell Mol Biol Lett 13:649-655.

Wong FK, Bercsenyi K, Sreenivasan V, Portalés A, Fernández-Otero M, Marín O (2018) Pyramidal cell regulation of interneuron survival sculpts cortical networks. Nature 557:668-673.

Yang Z, You Y, Levison SW (2008) Neonatal hypoxic/ischemic brain injury induces production of calretinin-expressing interneurons in the striatum. J Comp Neurol 511:19-33.

Zhang H, Fang X, Huang D, Luo Q, Zheng M, Wang K, Cao L, Yin Z (2018) Erythropoietin signaling increases neurogenesis and oligodendrogenesis of endogenous neural stem cells following spinal cord injury both in vivo and in vitro. Mol Med Rep 17:264-272.

Zhu LX, Bai S, Wang Y, Hu T, Wang L, Qian L Jiang (2014) Recombinant human erythropoietin augments angiogenic responses in a neonatal rat model of cerebral unilateral hypoxia-ischemia. Neonatology 106:143-148. 